Electronic supplementary information to:

\title{
Structure and surface complexation at the calcite(104)-water interface
}

Authors:

Frank Heberling ${ }^{1 *}$, Tin Klačić ${ }^{2}$, Paolo Raiteri ${ }^{3}$, Julian D. Gale³, Peter J. Eng ${ }^{4}$, Joanne E. Stubbs ${ }^{4}$, Teba

Gil-Díaz $^{1,5}$, Tajana Begović ${ }^{2}$, Johannes Lützenkirchen ${ }^{1}$

Affiliations:

1) Institute for Nuclear Waste Disposal, Karlsruhe Institute of Technology, PO Box 3640, 76021

Karlsruhe, Germany

2) Division of Physical Chemistry, Department of Chemistry, Faculty of Science, University of Zagreb, Horvatovac 102A, HR-10000 Zagreb, Croatia

3) Curtin Institute for Computation/The Institute for Geoscience Research, School of Molecular and Life Sciences, Curtin University, PO Box U1987 Perth, WA 6845, Australia

4) Center for Advanced Radiation Sources, The University of Chicago, 5734 South Ellis Avenue, Chicago, IL 60637, USA

5) Institute of Geosciences, Friedrich-Schiller-Universität Jena, Burgweg 11, 07749 Jena, Germany

This electronic supplementary information (ESI) file contains 14 Figures and 6 Tables on 27 pages. 


\section{Glossary of abbreviations and symbols}

\begin{tabular}{|c|c|c|}
\hline Abbreviation & Meaning & Description \\
\hline SCM & Surface complexation model & $\begin{array}{l}\text { Model for surface chemical reactions on the } \\
\text { basis of law of mass action equations and } \\
\text { electrostatic laws. }\end{array}$ \\
\hline TPM & Three plane model & $\begin{array}{l}\text { Special type of SCM subdividing the Stern } \\
\text { layer into } 3 \text { layers }\end{array}$ \\
\hline FLM & Four layer model & $\begin{array}{l}\text { Special type of SCM subdividing the Stern } \\
\text { layer into } 4 \text { layers }\end{array}$ \\
\hline IB & Ion binding constant & $\begin{array}{l}\text { Equilibrium constant for binding of an ion to a } \\
\text { surface functional group }\end{array}$ \\
\hline K & Equilibrium constant & \\
\hline MUSIC & Multi site ion complexation & $\begin{array}{l}\text { Empirical model relating equilibrium constants } \\
\text { for surface protonation to the interface } \\
\text { structure [16] }\end{array}$ \\
\hline $\mathrm{CD}$ & Charge distribution & $\begin{array}{l}\text { Model for the distribution of ion charges } \\
\text { between the planes of an SCM }\end{array}$ \\
\hline SCrE & Single crystal electrode & Cf. Figure S2 \\
\hline MD & Molecular dynamics & $\begin{array}{l}\text { Theoretical method to sample molecular } \\
\text { interactions on the basis of empirical force- } \\
\text { fields (e.g. RigidFF and AMOEBA, see below) }\end{array}$ \\
\hline AIMD & Ab initio molecular dynamics & $\begin{array}{l}\text { Here used for MD on the basis of density } \\
\text { functional theory, instead of force-fields. }\end{array}$ \\
\hline CTR & Crystal truncation rod & $\begin{array}{l}\text { Lines of diffracted intensity perpendicular to a } \\
\text { surface, containing information about the } \\
\text { molecular scale surface structure. The } \\
\text { abbreviation is used as name for the method } \\
\text { to determine the interface structure from X- } \\
\text { ray diffraction data. }\end{array}$ \\
\hline RAXR & $\begin{array}{l}\text { Resonant anomalous x-ray } \\
\text { reflectivity }\end{array}$ & $\begin{array}{l}\text { Special type of CTR measurement exploiting } \\
\text { resonant effects }\end{array}$ \\
\hline SXRD & Surface $x$-ray diffraction & Umbrella term for methods like CTR or RAXR \\
\hline ML & Mono-layer & Single layer of atoms / ions / molecules \\
\hline $\mathrm{SI}$ & Supporting information & \\
\hline AFM & Atomic force microscopy & \\
\hline
\end{tabular}




\section{Determination of free energies and binding constants from molecular dynamics simulations}

All classical molecular dynamics simulations were performed within 3D periodic boundary conditions using a $3 \mathrm{~nm}$ thick region of water sandwiched between a 10 layer-thick calcite slab (also approximately $3 \mathrm{~nm}$ in depth). The calcite slab was built from a bulk calcite cell that had been previously relaxed at $300 \mathrm{~K}$ and $1 \mathrm{bar}$, oriented with the (104) surface normal parallel to the z-axis and it contained a $5 \times 4$ repeat of the calcite surface unit cell. In the case of the unbiased MD simulations with a finite concentration electrolyte we used a $10 \times 8$ supercell to improve the statistics of the simulations. A region of water with the same area as the calcite surface was then added on top of the calcite slab and the cell was further relaxed in the $z$ direction to ensure that the water had its equilibrium density in the middle of the slab.

In order to study the ion distribution above the calcite surface in the presence of a finite concentration electrolyte solution we performed a series of unbiased $20 \mathrm{~ns}$ long MD simulations with various salts dissolved in the water layer. From the simulation of solutions containing $0.5 \mathrm{M} \mathrm{NaCl}, 0.25 \mathrm{M} \mathrm{CaCl}_{2}, 0.25$ $\mathrm{M} \mathrm{Na}_{2} \mathrm{CO}_{3}$ or $0.5 \mathrm{M} \mathrm{NaHCO}_{3}$ we extracted the ion density profile as a function of their position above the calcite surface, $\rho(z)$, which can be directly related to the adsorption free energy profile using the following relationship;

$$
\Delta G(z)=-R T \ln \left[\frac{\rho(z)}{\rho_{0}}\right]
$$

where $\rho_{0}$ is the density of the ions in the bulk water.

All production simulations were performed in the NVT ensemble at $300 \mathrm{~K}$ with a $1 \mathrm{fs}$ timestep using LAMMPS $^{1}$ and OpenMM ${ }^{2}$ for the rigid ion and AMOEBA force fields, respectively ${ }^{3}$. The long-range electrostatics were treated with the PPPM and PME algorithms using a precision of $10^{-5}$. OpenMM was run on a GPU cluster using mixed precision.

Multiple walker, well-tempered metadynamics simulations were used to compute the adsorption free energies of $\mathrm{Na}^{+}, \mathrm{Ca}^{2+}, \mathrm{HCO}_{3}{ }^{-}, \mathrm{CO}_{3}{ }^{2-}$ and $\mathrm{Cl}^{-}$on the calcite basal plane using a separate simulation with a single ion in the aqueous region. The ions were confined to move inside a cylinder of height $12 \AA$ above their adsorption site, which was identified as a surface ion of opposite charge. The cylinder had a radius of $1 \AA$ where no potential was applied and outside that radius a harmonic restraining potential was applied to keep the ion inside the cylinder. The potential had a spring constant of $1 \mathrm{eV} / \AA^{2}$ for the rigid ion force field and of $10,000 \mathrm{~kJ} /\left(\mathrm{mol} \mathrm{nm}^{2}\right)$ (approximately $\left.1 \mathrm{eV} / \AA^{2}\right)$ for the AMOEBA force field simulations.

The vertical distance above the surface was used as a collective variable in all simulations, which was computed as the distance between the adsorbate (using the position of $\mathrm{C}$ in the case of carbonate) and an ion in the middle of the calcite slab that was exactly below the adsorption site, minus the average vertical distance between that ion adsorption site (approximately $12 \AA$ ). For the calculation of the adsorption free energy of the anions the coordination number of the $\mathrm{Ca}$ at the adsorption site was used as a supplementary collective variable. This was to mitigate the problem of the slow water dynamics around the calcium ion, which is of the order of few $n$ s for both force field models. The initial Gaussian height was set to $k_{B} T$ and was progressively reduced following the well-tempered procedure using a bias factor of 5 . The widths of the Gaussians were $0.1 \AA$ and 0.1 for the distance and coordination number collective variables, respectively. All simulations were run for a combined total of at least $300 \mathrm{~ns}$, which was deemed sufficient to achieve convergence of the free energy calculations.

It is known that the presence of restraining potential can affect the computed free energy profiles, even when applied to a different reaction coordinate. Hence, to estimate this effect we performed a 
further $300 \mathrm{~ns}$ of MD with a constant bias potential (i.e. no more Gaussians were added) that was then used to reconstruct the free energy using a standard re-weighting approach. Only in the case of the carbonate adsorption, as computed with the rigid ion force field, was it found that the free energy profile obtained from the re-weighting procedure was significantly different from the metadynamics one (Figure S9). Specifically, although the free energy difference between the adsorbed state and the ion in solution was very similar, in the re-weighted free energy the most stable adsorption state is about $5 \AA$ above the surface rather than $3 \AA$ above the surface, which corresponds to the approximate positions of the third and second water layers, respectively.

From a mechanistic point of view, the adsorption process can be described as the adsorbing ion replacing a water molecule that is sitting immediately above the adsorption site. In the case of the anions this corresponds to a water molecule in the first water layer, which is tightly bound to a surface calcium ion. On the other hand, for the cations this means replacing a water molecule in the second water layer, which is bound to a surface carbonate. From an energetic point of view, it makes therefore sense that the cations have stronger adsorption free energies than the anions.

It is worth mentioning here that there is some ambiguity about what is the reference state of the adsorption free energies computed both from the metadynamics and density profile calculations. In fact, in order to correctly reference our calculation to a 1 molar solution, we would need to integrate the free energy profiles over the bound state and then correct for the difference in the available volume between the bound state and an ideal 1 molar solution. However, the definition of the bound state is somewhat arbitrary, which in turns make the calculation of the volume of the bound state unreliable. However, because all simulations were performed with the same protocol, we believe that the trend in the adsorption free energies is reliable, even if there is an uncertainty in their absolute values.

The above classical molecular dynamics simulations have also been complemented by $a b$ initio molecular dynamics (AIMD) based on dispersion-corrected density functional theory at the BLYPD3/TZV2P level ${ }^{4-6}$. All calculations were performed using the Quickstep approach ${ }^{7}$ within the CP2K code $^{8}$ with GTH pseudopotentials ${ }^{9}$ and an auxiliary planewave basis set with a cutoff of 400 Ry. Given the computationally demanding nature of such simulations for large systems (1,162 atoms in the present case) it is impractical to perform free energy evaluations for all the scenarios examined classically. Hence, we have used this approach in the case of one ion to address the question of whether contact adsorption with the calcite surface is possible or not. Here we focus on the case of chloride binding to the aqueous-calcite interface as a case where AMOEBA shows a clear minimum for the surface contact state, while the rigid ion model only has what is essentially a point of inflection. While it would be arguably more interesting to examine the case of carbonate adsorption, this is more problematic given that we have recently shown that this level of Kohn-Sham density functional theory fails to correctly localize the charge of the dianion in water, thereby leading to errors in the thermodynamics of ion association ${ }^{3}$.

For the AIMD runs, an orthorhombic cell $\left(14.973 \times 16.194 \times 51.0 \AA^{3}\right)$ was created containing six layers of calcite (with 72 formula units) separated by a region of water in the direction of the $c$ axis containing 267 molecules and a single chloride ion. The system was initially equilibrated using the rigid ion force field before further equilibration with AIMD in the NVT ensemble with a timestep of $0.5 \mathrm{fs}$ and use of the CSVR thermostat at a temperature of $330 \mathrm{~K}$. This elevated temperature is used to partially correct for the systematic over-structuring of water exhibited by GGA functionals, as recommend elsewhere. Because the objective is not to determine the full free energy profile, but a more focused aim of trying to determine whether a contact state exists for the chloride ion at the calcite surface and, if so, how stable it is relative to the solvent-shared state, we have used umbrella sampling to map this region of the landscape. Two collective variables were again used; the first is the $\mathrm{z}$ height of the $\mathrm{Cl}^{-}$ion relative 
to the underlying calcium of the calcite surface, while the second is the water-coordination number of the surface calcium ion in order to overcome the slow rate of exchange of ligands, at least on the AIMD timescale (the parameters for the water coordination number are exponents of 8 and 16 with an $r_{0}$ of 3.0 ̊). The spring constants for the 64 umbrellas were $0.5 \mathrm{eV} / \AA^{2}$ and $0.05-0.25 \mathrm{au}$, respectively.

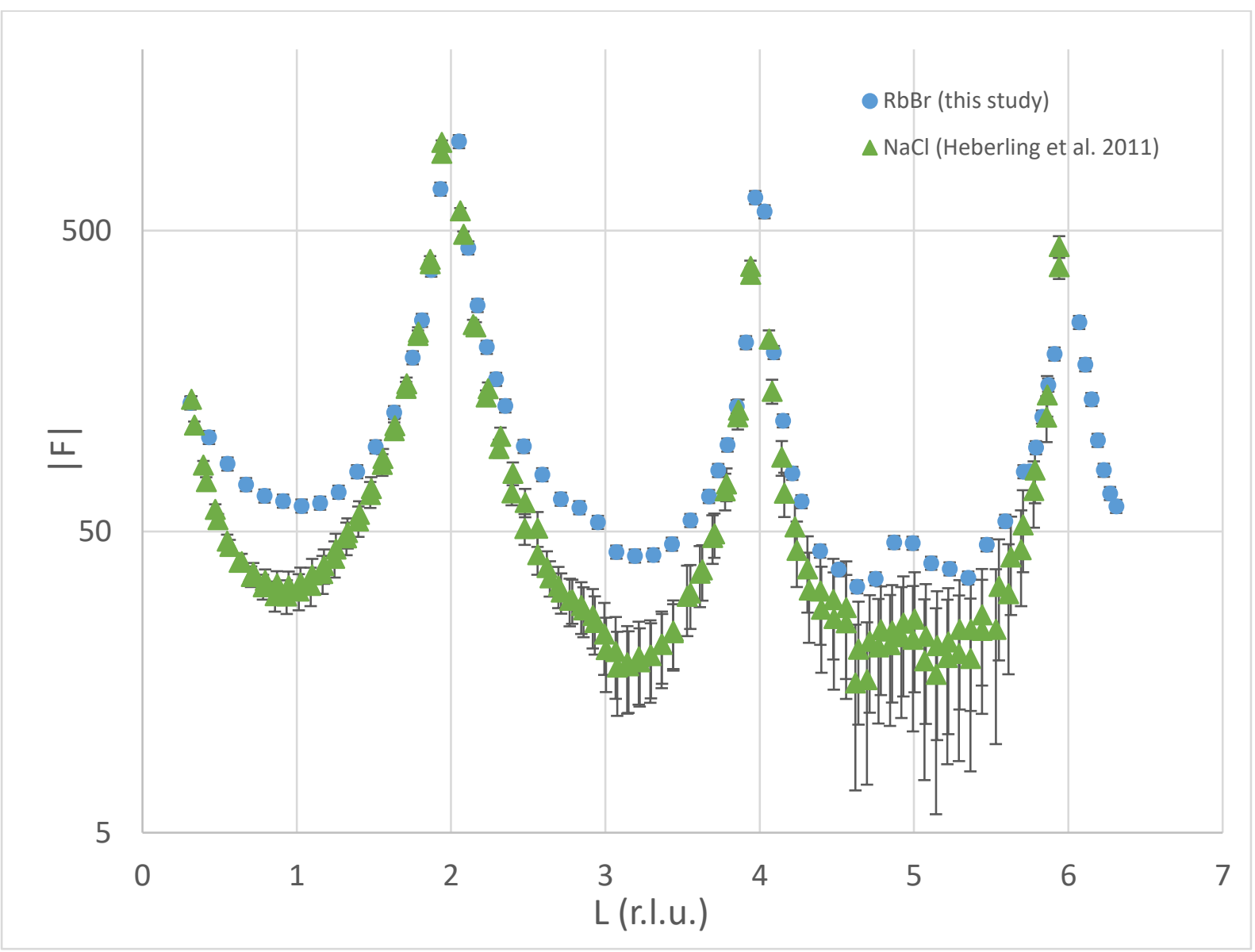

Figure S1: Comparison between (0OL) CTRs measured in $10 \mathrm{mmol} / \mathrm{L} \mathrm{RbBr}$ (this study, blue circles) and in $100 \mathrm{mmol} / \mathrm{L} \mathrm{NaCl}$ (Heberling et al., $2011^{10}$, green triangles) equilibrium solutions (pH $8.2-8.3$ ). Note that the lower intensities between Bragg peaks for the sample in $\mathrm{NaCl}$ solution are due to the rougher surface of this calcite sample (beta $=0.03 \pm 0.01)^{11}$ compared to the newer measurements in $\mathrm{RbBr}$ solution (beta $=0.0$ ). Otherwise the features of the CTRs, e.g. the shoulder at $L=2.8$ to 2.9 and the small peak around $L=4.9$, are present in both data sets. This corroborates findings from previous studies ${ }^{10,12}$ that the composition of the solution has no significant impact on the calcite-water interface structure. Also note the dramatically decreased uncertainties of the new dataset (error bar size corresponds roughly to the symbol size), which is mainly due to strongly improved data acquisition and data integration routines compared to previous measurements ${ }^{10}$. 
Table S1: Composition of the nine suspensions used for equilibrium measurements with the calcite $\mathrm{SCrE}$; initial additions and equilibrium composition as calculated with Phreeq $\mathrm{C}^{13}$ and the PSINA.dat ${ }^{14}$ database. The last column shows the expected solution conditions during CTR measurements.

\begin{tabular}{|c|c|c|c|c|c|c|c|c|c|c|}
\hline $\begin{array}{l}\text { pH } \\
\text { (nominal) }\end{array}$ & 7.50 & 7.75 & 8.00 & 8.25 & 8.50 & 8.75 & 9.00 & 9.25 & 9.50 & CTR \\
\hline $\begin{array}{l}\text { pH } \\
\text { (after } 75 \\
\text { days } \\
\text { equilibration) }\end{array}$ & 7.53 & 7.70 & 7.97 & 8.20 & 8.48 & 8.97 & 9.19 & 9.53 & 9.82 & 8.20 \\
\hline & \multicolumn{9}{|c|}{ initial composition } & \\
\hline $\begin{array}{l}\text { Solid / liquid } \\
\text { ratio (initial, } \\
\text { g/L) }\end{array}$ & 1.0 & 1.0 & 1.0 & 1.0 & 1.0 & 1.0 & 1.0 & 1.0 & 1.0 & $\begin{array}{l}\text { ca. } \\
1.0\end{array}$ \\
\hline $\begin{array}{l}\mathrm{NaCl} \\
\text { (mmol/L) }\end{array}$ & 5 & 70 & 90 & 100 & 100 & 100 & 100 & 80 & 60 & $\begin{array}{c}10 \\
(\mathrm{RbBr})\end{array}$ \\
\hline $\mathrm{HCl}(\mathrm{mmol} / \mathrm{L})$ & 68.0 & 20.9 & 6.0 & 0.8 & - & - & - & - & - & - \\
\hline $\begin{array}{l}\mathrm{NaOH} \\
(\mathrm{mmol} / \mathrm{L})\end{array}$ & - & - & - & - & 1.8 & 4.6 & 9.6 & 20.0 & 46.3 & - \\
\hline \multirow[t]{2}{*}{$x\left(\mathrm{CO}_{2}\right)(\mathrm{ppm})$} & 360 & 360 & 360 & 360 & 360 & 360 & 360 & 360 & 360 & 450 \\
\hline & \multicolumn{9}{|c|}{ calculated equilibrium composition } & \\
\hline $\begin{array}{l}\text { lonic } \\
\text { strength } \\
\text { (mmol/L) }\end{array}$ & 107.2 & 101.9 & 100.0 & 103.2 & 102.8 & 104.8 & 109.6 & 100.2 & 107.5 & 11.8 \\
\hline $\begin{array}{l}\mathrm{Ca}^{2+} \\
(\mathrm{mmol} / \mathrm{L})\end{array}$ & 34.06 & 10.62 & 3.34 & 1.07 & 0.34 & 0.11 & 0.03 & 0.01 & $<0.01$ & 0.63 \\
\hline $\begin{array}{l}\mathrm{CO}_{3}^{2-} \\
(\mathrm{mmol} / \mathrm{L})\end{array}$ & $<0.01$ & $<0.01$ & 0.01 & 0.02 & 0.07 & 0.21 & 0.68 & 2.11 & 6.80 & 0.01 \\
\hline $\begin{array}{l}\mathrm{HCO}_{3}^{-} \\
(\mathrm{mmol} / \mathrm{L})\end{array}$ & 0.22 & 0.39 & 0.70 & 1.24 & 2.20 & 3.92 & 7.00 & 12.36 & 22.10 & 1.22 \\
\hline
\end{tabular}
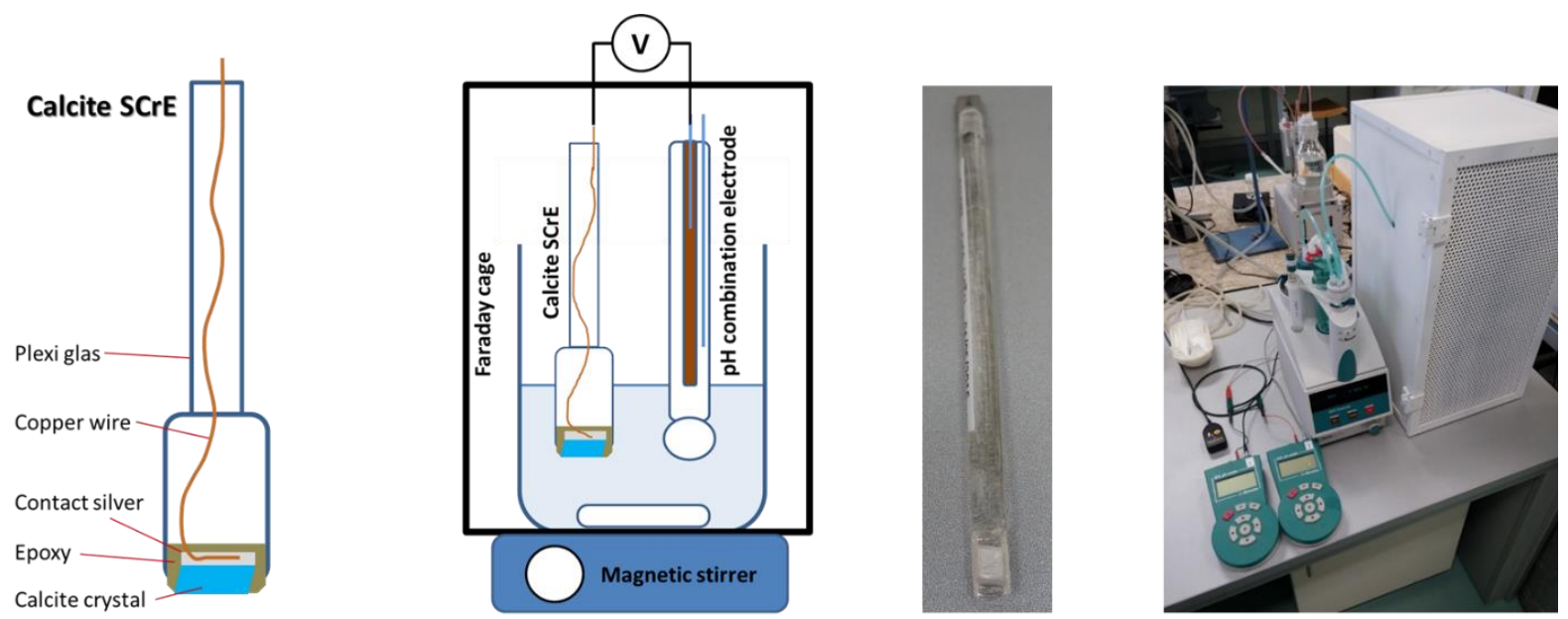

Figure S2: Schematics (left) and photographs (right) of the SCrE and the measurement setup used for the SCrE investigations. The potential delivered by the $\mathrm{SCrE}$ is measured against the potential of the reference electrode inside a $\mathrm{pH}$-combination glass electrode, which is immersed in the same solution. This set-up allows parallel pH- and SCrE-potential measurements. The measurements are very sensitive to any disturbing signals. Therefore, beaker and electrodes are placed in a Faraday cage, and the magnetic stirrer is turned off during data acquisition. The absolute value of the potential is affected by 
side-effects like e.g. junction potentials. Therefore, it is not the absolute values which are finally considered as model constraints, but rather the changes in potential as a function of changes in the solution composition.
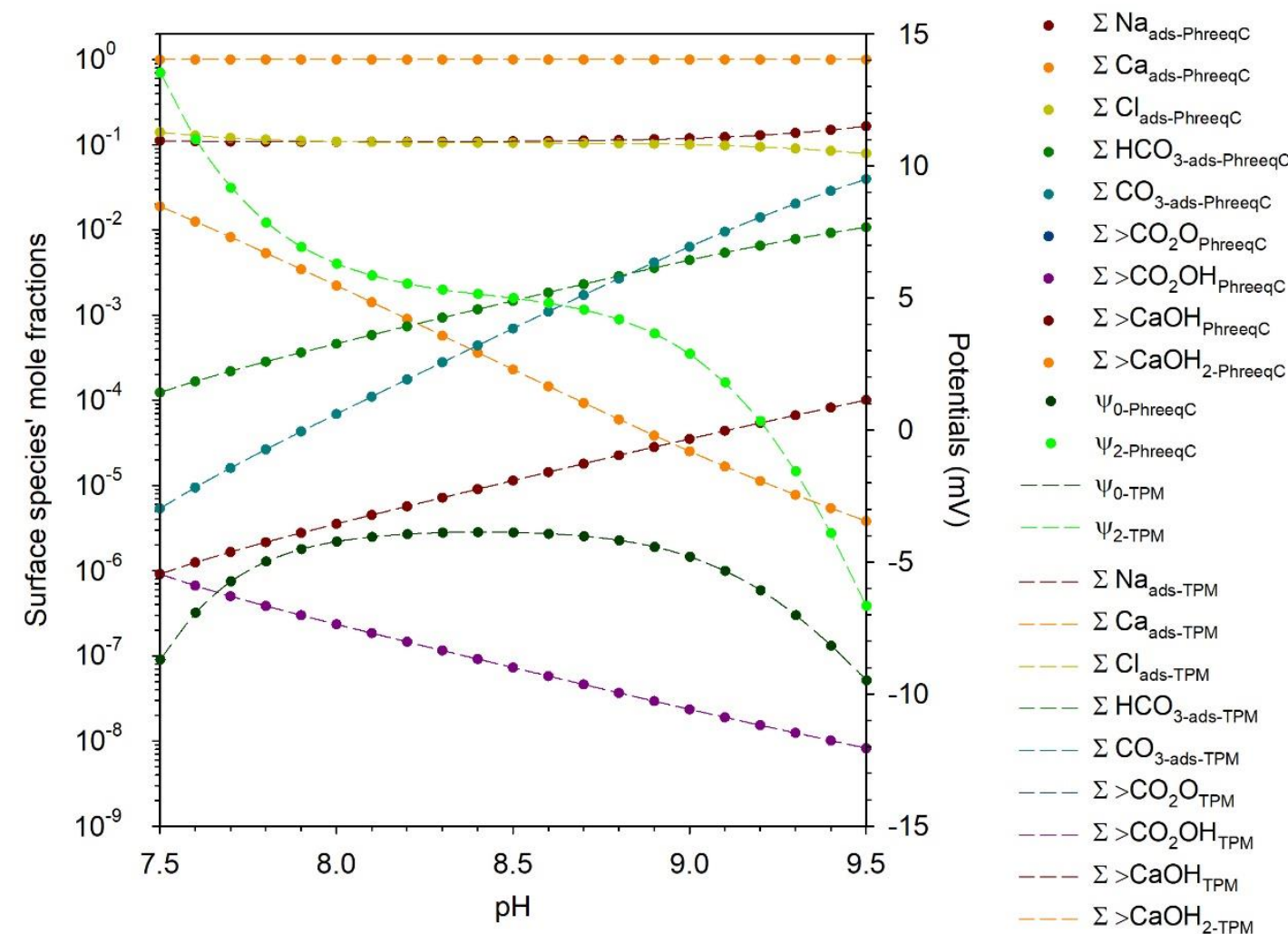

Figure S3: Benchmarking of the FLM code against PhreeqC. To do this, the TPM was implemented in the FLM code. The unnecessary third layer capacitance (between 2- and 3-plane) was set to a high value $\left(10^{7} \mathrm{~F} / \mathrm{m}^{2}\right)$ to set $\psi_{2} \approx \psi_{3}$. The resulting speciation agrees perfectly with the original TPM implementation in PhreeqC. 


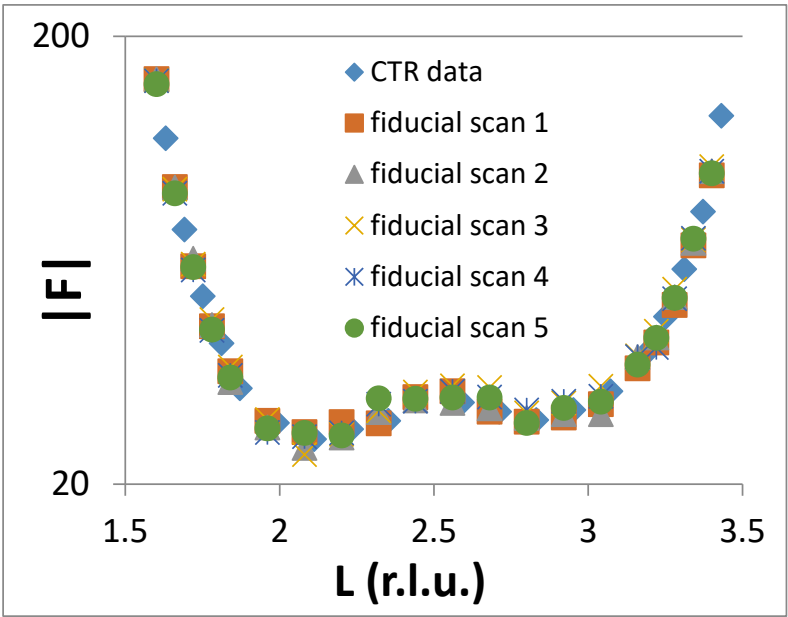

Figure S4: CTR data and fiducial scans measured on the $(-20 \mathrm{~L})$ CTR, before (fiducial scan 1$)$, throughout (fiducial scans $2-4$ ), and after (fiducial scan 5) the acquisition of the CTR dataset. The nearly perfect reproducibility of the fiducial measurements demonstrates the stability of the sample throughout data collection.
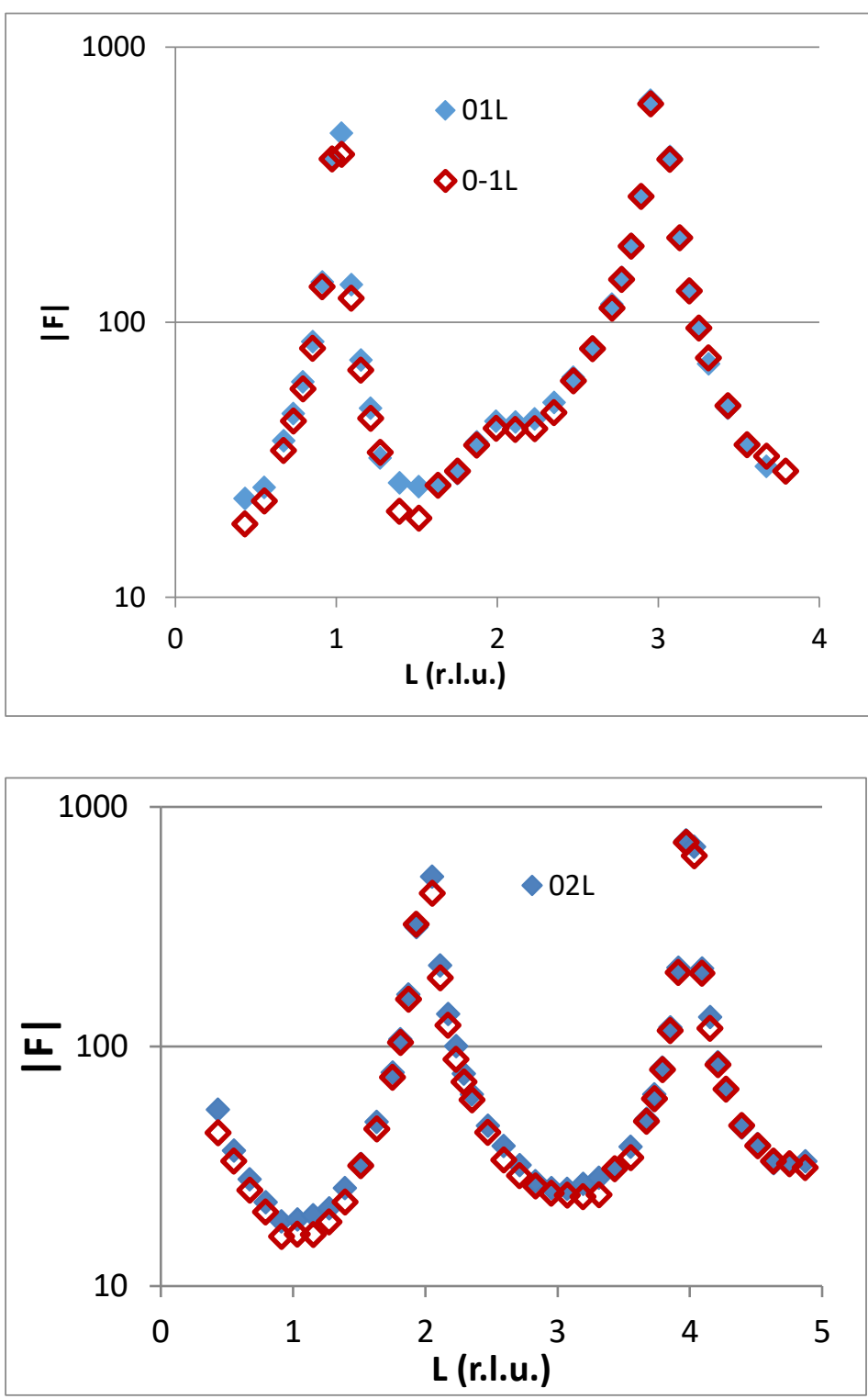

Figure S5: Symmetry equivalent (01L) and (0 -1L) CTRs (upper plot) as well as (02L) and (0 -2L) CTRs (lower plot) demonstrate the minor systematic error affecting the CTR data collection. On the basis of fiducial scans (Figure S2) and symmetry-equivalent CTRs in this Figure, it was decided that the most reasonable treatment of uncertainties is to assign a constant relative uncertainty of $5 \%$ to all CTR data. 
Table S2: CTR model parameters determined by structure refinement.

\begin{tabular}{|c|c|c|c|}
\hline Parameter & Value & $\begin{array}{l}\text { Standard } \\
\text { deviation }\end{array}$ & Comment \\
\hline \multicolumn{4}{|c|}{ Surface roughness $^{11}$} \\
\hline beta & 0.0 & & Application of roughness model not necessary \\
\hline \multicolumn{4}{|c|}{ Layered water profile $^{15}$} \\
\hline z-water & $3.82 \AA$ & $0.03 \AA$ & Onset of layered water profile above the surface \\
\hline d-water & $1.8 \AA$ & $0.3 \AA$ & Inter-layer-spacing of layered water profile \\
\hline$\sigma$-water & $0.7 \AA^{2}$ & $0.1 \AA^{2}$ & Gaussian width of $1^{\text {st }}$ bulk water layer \\
\hline $\bar{\sigma}$-water & $0.4 \AA^{2}$ & $0.4 \AA^{2}$ & Gaussian width added to each consecutive water layer \\
\hline \multicolumn{4}{|c|}{ Adsorbed structural water } \\
\hline $\mathrm{dx}\left(\mathrm{H}_{2} \mathrm{O}-2\right)$ & $0.028 \AA$ & $0.005 \AA$ & $\mathrm{dx}$ denotes shift in $\mathrm{x}$-direction \\
\hline dy $\left(\mathrm{H}_{2} \mathrm{O}-2\right)$ & $-0.091 \AA$ & $0.002 \AA$ & dy denotes shift in y-direction \\
\hline $\mathrm{dz}\left(\mathrm{H}_{2} \mathrm{O}-2\right)$ & $0.073 \AA$ & $0.004 \AA$ & $\mathrm{dz}$ denotes shift in $\mathrm{z}$-direction \\
\hline $\mathrm{DW}\left(\mathrm{H}_{2} \mathrm{O}-2\right)$ & aniso & & $\begin{array}{l}\text { see below, Table } S 3 \text {, } \\
\text { DW stands for Debye-Waller-Factor, reported values } \\
\text { correspond to } U_{\text {iso }} \text { parameters }\end{array}$ \\
\hline $\operatorname{occ}\left(\mathrm{H}_{2} \mathrm{O}-2\right)$ & 0.67 & 0.15 & occ stands for site occupancy \\
\hline $\mathrm{dx}\left(\mathrm{H}_{2} \mathrm{O}-1\right)$ & $0.135 \AA$ & $0.003 \AA$ & \\
\hline dy $\left(\mathrm{H}_{2} \mathrm{O}-1\right)$ & $-1.015 \AA$ & $0.002 \AA$ & \\
\hline $\mathrm{dz}\left(\mathrm{H}_{2} \mathrm{O}-1\right)$ & $-0.072 \AA$ & $0.003 \AA$ & \\
\hline $\mathrm{DW}\left(\mathrm{H}_{2} \mathrm{O}-1\right)$ & aniso & & see below, Table S3 \\
\hline $\mathrm{OCC}\left(\mathrm{H}_{2} \mathrm{O}-1\right)$ & 1.0 & & fixed at upper limit \\
\hline \multicolumn{4}{|c|}{ First mono-layer } \\
\hline $\mathrm{dx}(\mathrm{Ca} 1)$ & $-0.017 \AA$ & $0.003 \AA$ & \\
\hline dy (Ca1) & $0.0038 \AA$ & $0.0007 \AA$ & \\
\hline $\mathrm{dz}$ (Ca1) & $-0.0340 \AA$ & $0.0004 \AA$ & \\
\hline DW (Ca1) & aniso & & see below, Table S3 \\
\hline $\mathrm{dx}$ (Carb1) & $-0.030 \AA$ & $0.004 \AA$ & \\
\hline dy (Carb1) & $0.0014 \AA$ & $0.0008 \AA$ & \\
\hline $\mathrm{dz}$ (Carb1) & $-0.030 \AA$ & $0.001 \AA$ & \\
\hline theta (Carb1) & $-4.2^{\circ}$ & $0.2^{\circ}$ & teta is the rotation around the a-axis \\
\hline phi (Carb1) & $-42.0^{\circ}$ & $0.1^{\circ}$ & $\begin{array}{l}\text { phi is the rotation around the b-axis, the bulk structural } \\
\text { position corresponds to phi }=-44.70^{\circ}\end{array}$ \\
\hline chi (Carb1) & $-4.2^{\circ}$ & $0.1^{\circ}$ & chi is the rotation around the c-axis \\
\hline DW (CCarb1) & $0.0127 \AA^{2}$ & & fixed at bulk value \\
\hline DW (01Carb1) & $0.0220 \AA^{2}$ & $0.0003 \AA^{2}$ & \\
\hline DW (O2Carb1) & aniso & & see below, Table S3 \\
\hline DW (O3Carb1) & $0.0220 \AA^{2}$ & $0.0003 \AA^{2}$ & set equal to DW(O1Carb1) \\
\hline \multicolumn{4}{|c|}{ Second mono-layer } \\
\hline $\mathrm{dx}(\mathrm{Ca} 2)$ & $0.014 \AA$ & $0.002 \AA$ & \\
\hline dy (Ca2) & $0.0151 \AA$ & $0.0002 \AA$ & \\
\hline $\mathrm{dz}(\mathrm{Ca} 2)$ & $0.0039 \AA$ & $0.0003 \AA$ & \\
\hline DW (Ca2) & $0.0127 \AA^{2}$ & & fixed at bulk value \\
\hline $\mathrm{dx}$ (Carb2) & $0.004 \AA$ & $0.003 \AA$ & \\
\hline dy (Carb2) & $0.0093 \AA$ & $0.0004 \AA$ & \\
\hline $\mathrm{dz}$ (Carb2) & $-0.016 \AA$ & $0.001 \AA$ & \\
\hline theta (Carb2) & $-2.8^{\circ}$ & $0.2^{\circ}$ & \\
\hline phi (Carb2) & $-43.93^{\circ}$ & $0.01^{\circ}$ & \\
\hline chi (Carb2) & $-2.4^{\circ}$ & $0.1^{\circ}$ & \\
\hline
\end{tabular}




\begin{tabular}{|c|c|c|c|}
\hline DW (CCarb2) & $0.013 \AA^{2}$ & $0.002 \AA^{2}$ & \\
\hline DW (OCarb2) & $0.0165 \AA^{2}$ & & fixed at bulk value \\
\hline \multicolumn{4}{|c|}{ Third mono-layer } \\
\hline $\mathrm{dx}$ (Ca3) & $-0.003 \AA$ & $0.002 \AA$ & \\
\hline dy (Ca3) & $-0.0033 \AA$ & $0.0002 \AA$ & \\
\hline $\mathrm{dz}$ (Ca3) & $-0.0043 \AA$ & $0.0002 \AA$ & \\
\hline DW (Ca3) & $0.0127 \AA^{2}$ & & fixed at bulk value \\
\hline $\mathrm{dx}$ (Carb3) & $-0.003 \AA$ & $0.002 \AA$ & \\
\hline dy (Carb3) & $0.0009 \AA$ & $0.0002 \AA$ & \\
\hline $\mathrm{dz}$ (Carb3) & $-0.0048 \AA$ & $0.0009 \AA$ & \\
\hline theta (Carb3) & $-1.4^{\circ}$ & $0.1^{\circ}$ & \\
\hline phi (Carb3) & $-45.27^{\circ}$ & $0.01^{\circ}$ & \\
\hline chi (Carb3) & $-0.6^{\circ}$ & $0.1^{\circ}$ & \\
\hline DW (CCarb3) & $0.0165 \AA^{2}$ & & fixed at bulk Oxygen value \\
\hline \multicolumn{4}{|c|}{ Fourth mono-layer } \\
\hline $\mathrm{dx}(\mathrm{Ca} 4)$ & $0.012 \AA$ & $0.001 \AA$ & \\
\hline dy (Ca4) & $0.0034 \AA$ & $0.0001 \AA$ & \\
\hline $\mathrm{dz}(\mathrm{Ca} 4)$ & $0.0045 \AA$ & $0.0001 \AA$ & \\
\hline DW (Ca4) & $0.0127 \AA^{2}$ & & fixed at bulk value \\
\hline $\mathrm{dx}$ (Carb4) & $-0.004 \AA$ & $0.001 \AA$ & \\
\hline dy (Carb4) & $0.0005 \AA$ & $0.0001 \AA$ & \\
\hline $\mathrm{dz}$ (Carb4) & $-0.0073 \AA$ & $0.0005 \AA$ & \\
\hline theta (Carb4) & 0 & & fixed \\
\hline phi (Carb4) & $-44.28^{\circ}$ & $0.02^{\circ}$ & \\
\hline chi (Carb4) & 0 & & fixed \\
\hline DW (Carb4) & $0.0165 \AA^{2}$ & & fixed at bulk Oxygen value \\
\hline
\end{tabular}

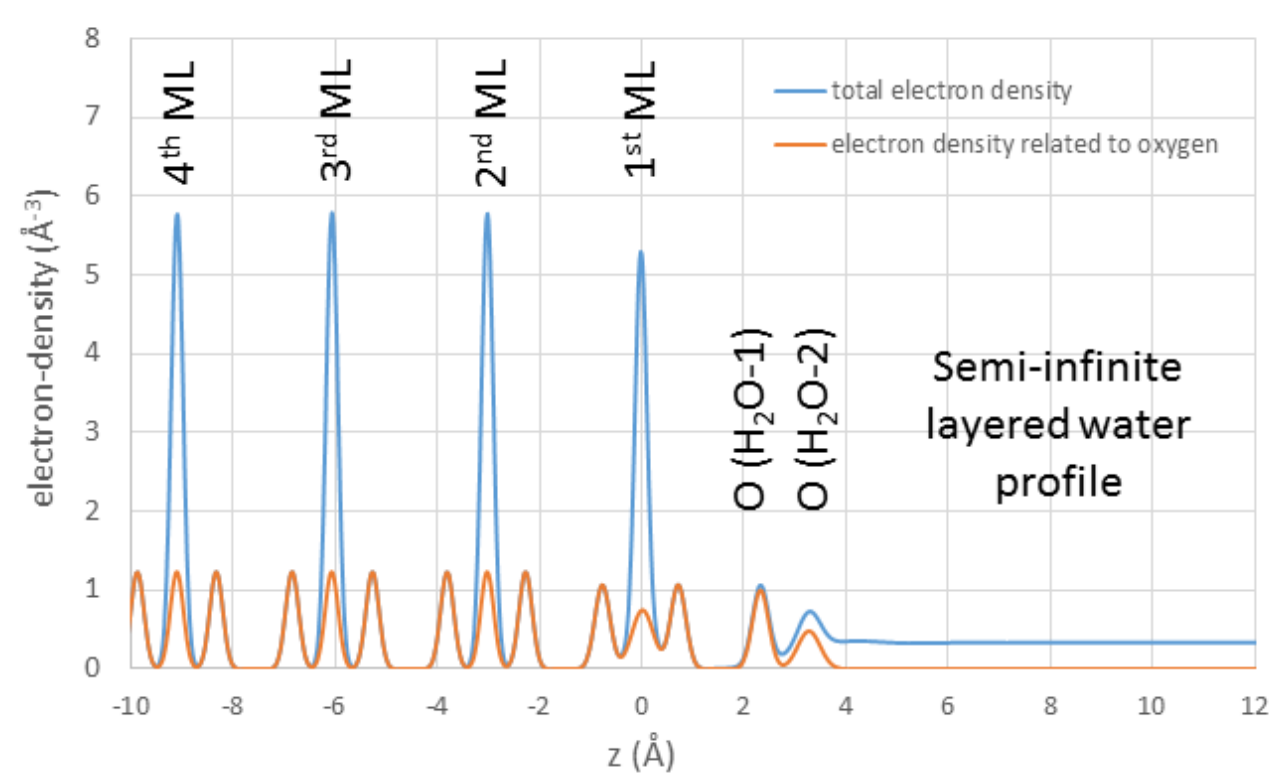

Figure S6: Electron density profile across the calcite-water interface as derived from CTR-data. The semi-infinite layered water profile ${ }^{15}$, which is assumed to be on top of the distinct interface atoms is depicted according to the parameters listed in Table S2. 
Table S3: Comparison of anisotropic Debye-Waller factors from CTR and MD. O $\left(\mathrm{H}_{2} \mathrm{O}-2\right)$ and $\mathrm{O}\left(\mathrm{H}_{2} \mathrm{O}-1\right)$ denote the oxygen atoms from water molecules in the second and first water-layers above the surface, respectively. Ca-1 denotes the calcium ion in the $1^{\text {st }}$ calcite monolayer. 0-2 (Carb-1) is the in-plane oxygen atom of the surface $\left(1^{\text {st }} \mathrm{ML}\right.$ ) carbonate moiety (cf. also Figure $\mathrm{S} 6$ and Figure 1 (main manuscript)).

\begin{tabular}{|c|l|c|c|c|c|c|c|}
\hline Atom & & $\mathbf{U x}\left[\AA^{2}\right]$ & $\mathbf{U}\left[\AA^{2}\right]$ & $\mathbf{U z}\left[\AA^{2}\right]$ & $|\mathbf{U x y}|$ & $|\mathbf{U x z}|$ & $\mid$ Uyz $\mid$ \\
\hline \multirow{2}{*}{$\mathrm{O}\left(\mathrm{H}_{2} \mathrm{O}-2\right)$} & $\mathrm{CTR}$ & 0.40 & 0.23 & 0.05 & 0.15 & 0.05 & 0.05 \\
\cline { 2 - 8 } & $\mathrm{MD}$ & 0.64 & 0.36 & 0.08 & 0.2 & 0.1 & 0.04 \\
\hline \multirow{2}{*}{$\mathrm{O}\left(\mathrm{H}_{2} \mathrm{O}-1\right)$} & $\mathrm{CTR}$ & 0.33 & 0.19 & 0.03 & 0.13 & 0.04 & 0.03 \\
\cline { 2 - 8 } & $\mathrm{MD}$ & 0.26 & 0.20 & 0.04 & 0.06 & 0.06 & 0.01 \\
\hline \multirow{2}{*}{$\mathrm{Ca}-1$} & $\mathrm{CTR}$ & 0.017 & 0.032 & 0.013 & 0 & 0 & 0 \\
\cline { 2 - 8 } & $\mathrm{MD}$ & 0.016 & 0.013 & 0.024 & $<0.01$ & $<0.01$ & $<0.01$ \\
\hline \multirow{2}{*}{$\mathrm{O}-2($ Carb-1) } & $\mathrm{CTR}$ & 0.040 & 0.040 & 0.045 & 0 & 0.017 & 0 \\
\cline { 2 - 8 } & $\mathrm{MD}$ & 0.010 & 0.019 & 0.073 & $<0.01$ & $<0.01$ & $<0.01$ \\
\hline
\end{tabular}


Figure S7: Atom positions (50\% probability regions) for calcite-water interface atoms as derived from original MD trajectories (left) and the same structure reproduced by adjusted anisotropic DebyeWaller factors (U-Tensors, right). Projection along the surface crystallographic a-axis (cf. Figure 1, bottom, middle). Marked with red circles in the right image are the atoms for which anisotropic DebyeWaller factors were considered during the CTR data analysis, and which are compared in Table S3. Color code: oxygen $\left(\mathrm{H}_{2} \mathrm{O}-2\right)$ : orange, oxygen $\left(\mathrm{H}_{2} \mathrm{O}-1\right)$ : yellow, oxygen (carbonate $\left.1^{\text {st }} \mathrm{ML}\right)$ : red, oxygen (carbonate $2^{\text {nd }} \mathrm{ML}$ ): pink, carbon: light blue, calcium: green 
Table S4: Best fit calcite SCM parameters

\begin{tabular}{|c|c|c|c|c|}
\hline Model & Best $f$ & SCM & & Data for comparison \\
\hline & Value & Std-dev & Value & Source \\
\hline $\log _{10} \mathrm{~K}_{\mathrm{CaOH}}$ & 13.38 & 0.01 & $13.8 \pm 0.8$ & MUSIC ${ }^{16}$ equation \\
\hline $\log _{10} \mathrm{~K}_{\mathrm{co} 3 \mathrm{H}}$ & 1.3 & 0.1 & $1.5 \pm 1.0$ & MUSIC ${ }^{16}$ equation \\
\hline $\log _{10} I \mathrm{~B}_{\mathrm{Na}}$ & 0.5 & 0.1 (fixed*) & 1.27 & Aqueous ion-pair formation constant ${ }^{14}$ \\
\hline $\log _{10} I B_{C a}$ & 0.68 & 0.02 & 3.23 & Aqueous ion-pair formation constant ${ }^{14}$ \\
\hline $\log _{10} I_{B_{\mathrm{HCO}}}$ & 0.37 & 0.09 & 1.11 & Aqueous ion-pair formation constant ${ }^{14}$ \\
\hline $\log _{10} I_{\mathrm{B}} \mathrm{CO}$ & 1.91 & 0.07 & 3.23 & Aqueous ion-pair formation constant ${ }^{14}$ \\
\hline $\log _{10} I B_{C I}$ & 0.6 & 0.2 & 0.5 & Aqueous ion-pair formation constant ${ }^{17}$ \\
\hline $\mathrm{C}_{1}\left(\mathrm{~F} / \mathrm{m}^{2}\right)$ & 0.2 & fixed & $0.1-0.3$ & Ice-like permittivity \\
\hline $\mathrm{C}_{2}\left(\mathrm{~F} / \mathrm{m}^{2}\right)$ & 1.5 & fixed & $1.4-3.5$ & Water-like permittivity \\
\hline $\mathrm{CD} \mathrm{Na}$ & $0.0,0.9,0.1$ & $\mathrm{~m} . \mathrm{a}^{* *}$ & & \\
\hline $\mathrm{CD} \mathrm{Ca}$ & $0.0,1.0,1.0$ & m.a & & \\
\hline $\mathrm{CD} \mathrm{HCO}_{3}$ & $0.0,-0.8,-0.2$ & m.a & & \\
\hline $\mathrm{CD} \mathrm{CO}_{3}$ & $0.0,-1.6,-0.4$ & m.a & & \\
\hline $\mathrm{CDCl}$ & $0.0,-1.0,0.0$ & m.a & & \\
\hline
\end{tabular}

*) fixed: Parameters denoted as fixed were optimized during preliminary SCM adjustment runs, but kept constant during the final optimization, in order to avoid obstructive effects of parameter correlations.

${ }^{* *}$ ) m.a: Parameters denoted m.a. in Table S4 were manually adjusted during SCM optimization

In the following, chemical reactions included in the SCM are reported in addition to the PhreeqC file at the end of this document, in a more classical sum formula type notation:

\begin{tabular}{|c|c|c|c|c|c|c|}
\hline$>\mathrm{CaOH}^{-0.5}$ & $+\mathrm{H}^{+}$ & $\rightleftharpoons$ & $>\mathrm{CaOH}_{2}{ }^{+0.5}$ & $; \log _{10} K_{>\mathrm{CaOH}}$ & \multicolumn{2}{|c|}{$=13.38 \pm 0.01$} \\
\hline$>\mathrm{CaOH}^{-0.5}$ & $+\mathrm{Na}^{+}$ & $\rightleftharpoons$ & $>\mathrm{CaOH} \cdots \mathrm{Na}^{+0.5}$ & $; \log _{10} \mid \mathrm{B}_{\mathrm{Na}}$ & $=0.5$ & \pm 0.1 \\
\hline$>\mathrm{CaOH}^{-0.5}$ & $+\mathrm{Ca}^{2+}$ & $\rightleftharpoons$ & $>\mathrm{CaOH} \cdots \mathrm{Ca}^{+1.5}$ & $; \log _{10} \mathrm{IB}_{\mathrm{Ca}}$ & $=0.68$ & \pm 0.02 \\
\hline$>\mathrm{CaOH}_{2}^{+0.5}$ & $+\mathrm{Cl}^{-}$ & $\rightleftharpoons$ & $>\mathrm{CaOH}_{2} \cdots \mathrm{Cl}^{-0.5}$ & $; \log _{10} \mid \mathrm{B}_{\mathrm{Cl}}$ & $=0.6$ & \pm 0.2 \\
\hline$>\mathrm{CaOH}_{2}{ }^{+0.5}$ & $+\mathrm{HCO}_{3}^{-}$ & $\rightleftharpoons$ & $>\mathrm{CaOH}_{2} \cdots \mathrm{HCO}_{3}^{-0.5}$ & $; \log _{10} \mathrm{IB}_{\mathrm{HCO}}$ & $=0.37$ & \pm 0.09 \\
\hline$>\mathrm{CaOH}_{2}{ }^{+0.5}$ & $+\mathrm{CO}_{3}^{2-}$ & $\rightleftharpoons$ & $>\mathrm{CaOH}_{2} \cdots \mathrm{CO}_{3}{ }^{-1.5}$ & ; $\log _{10} \mathrm{IB}_{\mathrm{CO}}$ & $=1.91$ & \pm 0.07 \\
\hline$>\mathrm{CO}_{2} \mathrm{O}^{-0.5}$ & $+\mathrm{H}^{+}$ & $\rightleftharpoons$ & $>\mathrm{CO}_{2} \mathrm{OH}^{+0.5}$ & $; \log _{10} K_{>} \cos _{3}$ & $=1.3$ & \pm 0.1 \\
\hline$>\mathrm{CO}_{2} \mathrm{O}^{-0.5}$ & $+\mathrm{Na}^{+}$ & $\rightleftharpoons$ & $>\mathrm{CO}_{2} \mathrm{O} \cdots \mathrm{Na}^{+0.5}$ & $; \log _{10} \mathrm{IB}$ Na & $=0.5$ & \pm 0.1 \\
\hline$>\mathrm{CO}_{2} \mathrm{O}^{-0.5}$ & $+\mathrm{Ca}^{2+}$ & $\rightleftharpoons$ & $>\mathrm{CO}_{2} \mathrm{O} \cdots \mathrm{Ca}^{+1.5}$ & ; $\log _{10} \mathrm{IB} \mathrm{Ca}$ & $=0.68$ & \pm 0.02 \\
\hline$>\mathrm{CO}_{2} \mathrm{OH}^{+0.5}$ & $+\mathrm{Cl}^{-}$ & $\rightleftharpoons$ & $>\mathrm{CO}_{2} \mathrm{OH} \cdots \mathrm{Cl}^{-0.5}$ & $; \log _{10} \mid \mathrm{B}_{\mathrm{Cl}}$ & $=0.6$ & \pm 0.2 \\
\hline$>\mathrm{CO}_{2} \mathrm{OH}^{+0.5}$ & $+\mathrm{HCO}_{3}^{-}$ & $\rightleftharpoons$ & $>\mathrm{CO}_{2} \mathrm{OH} \cdots \mathrm{HCO}_{3}{ }^{-0.5}$ & ; $\log _{10} \mathrm{IBHCO}_{3}$ & $=0.37$ & \pm 0.09 \\
\hline$>\mathrm{CO}_{2} \mathrm{OH}^{+0.5}$ & $+\mathrm{CO}_{3}^{2-}$ & $\rightleftharpoons$ & $>\mathrm{CO}_{2} \mathrm{OH} \cdots \mathrm{CO}_{3}^{-1.5}$ & ; $\log _{10} \mathrm{IB}_{\mathrm{CO} 3}$ & $=1.91$ & \pm 0.07 \\
\hline
\end{tabular}




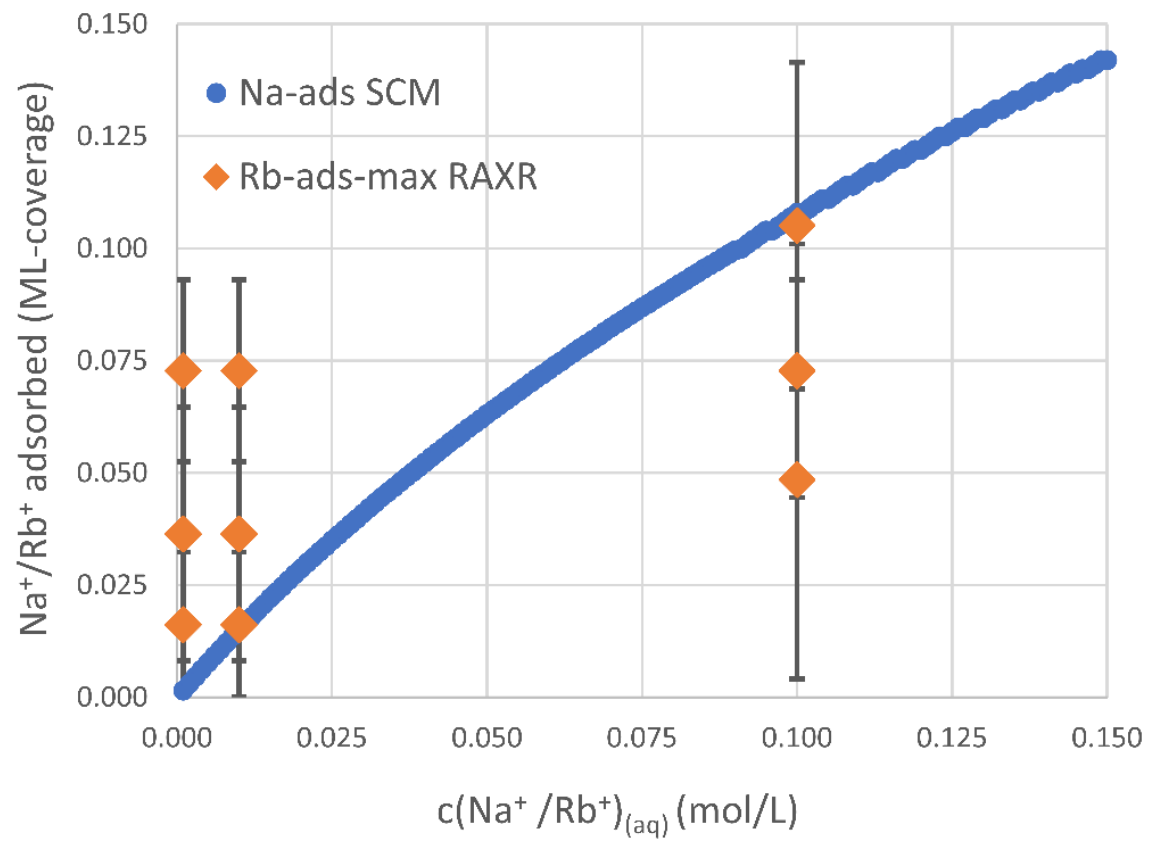

Figure S8: Surface monolayer coverage with adsorbed $\mathrm{Na}^{+}$in equilibrium with air and calcite according to the SCM, compared with upper-limits for $\mathrm{Rb}^{+}$adsorption as determined from RAXR investigations ${ }^{18}$. 


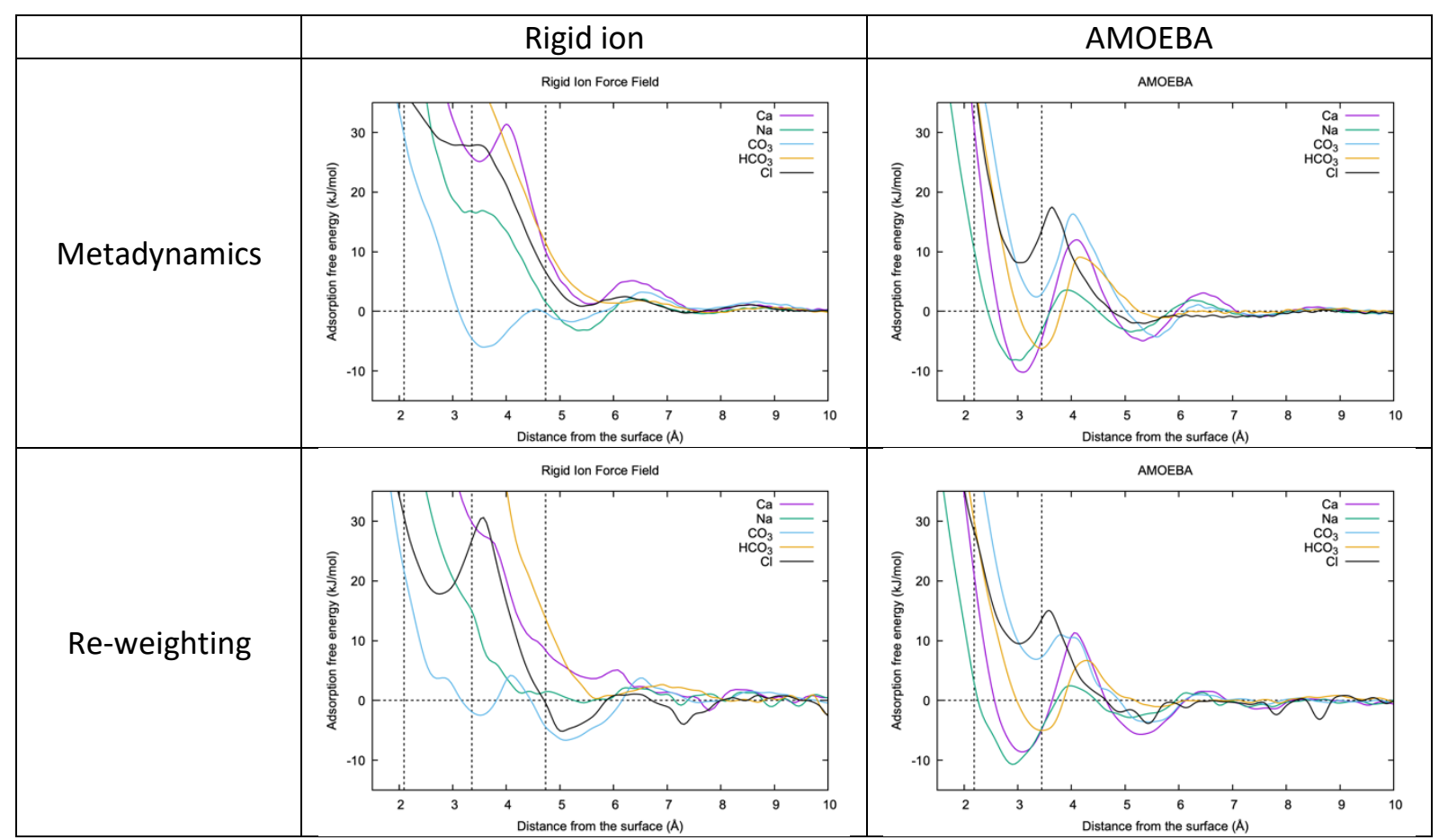

Figure S9: Adsorption free energy profiles obtained from the MD simulations using the rigid ion (left) and AMOEBA (right) force fields as obtained directly from the metadynamics simulations (top) or from a re-weighting procedure (bottom) where the effect of the cylindrical restraint used to limit the lateral mobility of the adsorbate has been removed. Both procedures give similar results, corroborating the validity of the methodology. The most noticeable difference is in the rigid ion force field calculations, where the most stable adsorption position for carbonate shifts above the third water layer. The reweighting free energy also appears a bit noisier due to the limited number of frames that were used to compute the free energy from the weighted histogram. Dashed lines indicate the positions of the $1^{\text {st }}, 2^{\text {nd }}$, and $3^{\text {rd }}$ water layer, respectively. 


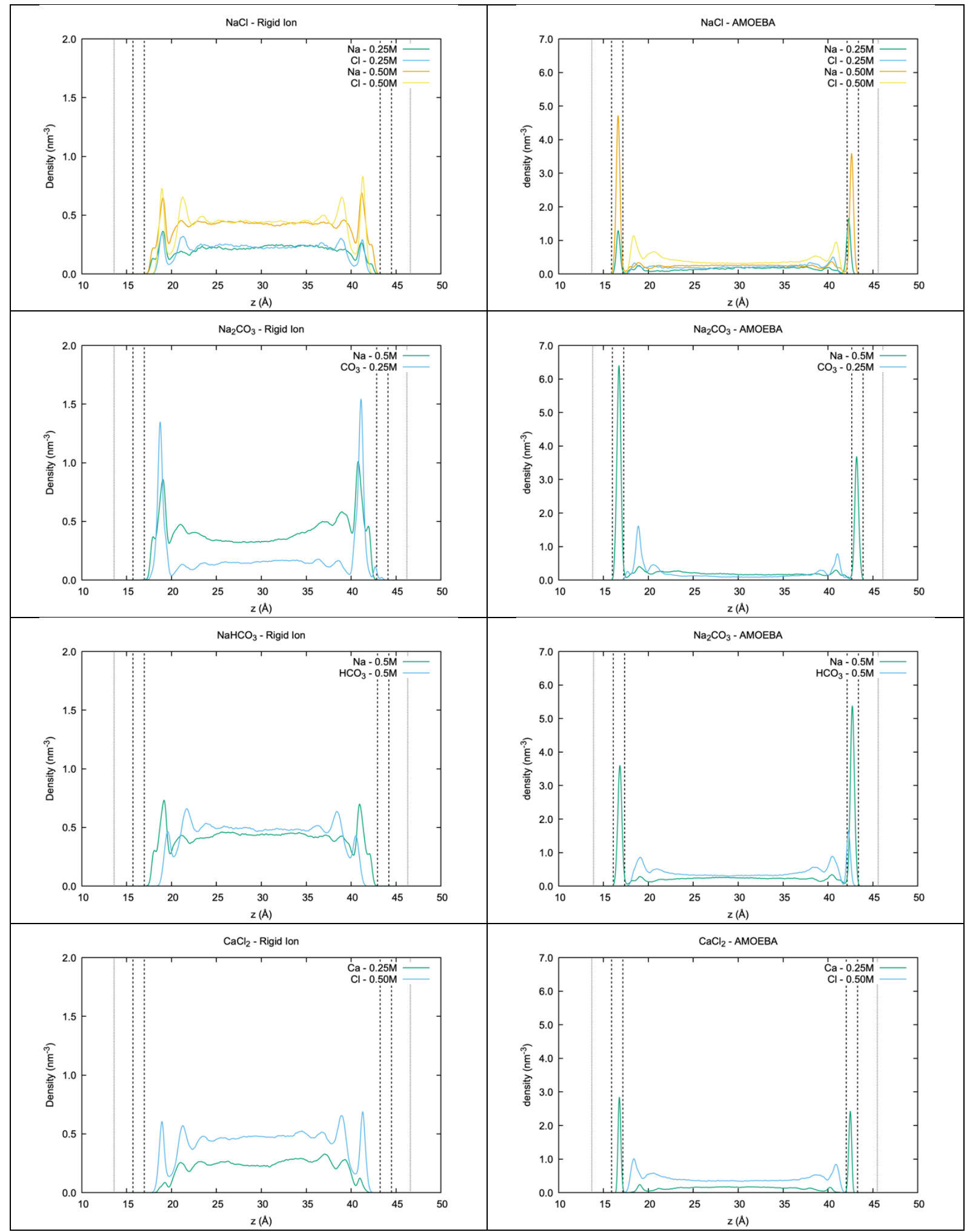

Figure S10: Ion density profiles obtained from the MD simulations using the rigid ion (left) and AMOEBA polarizable (right) force fields. The water region is sandwiched between two calcite slabs; the position of the mineral surfaces (dotted lines) was computed as the average position of the surface $\mathrm{Ca}$ ions. The dashed vertical lines indicate the positions of the two ordered water layers above the mineral surfaces. 


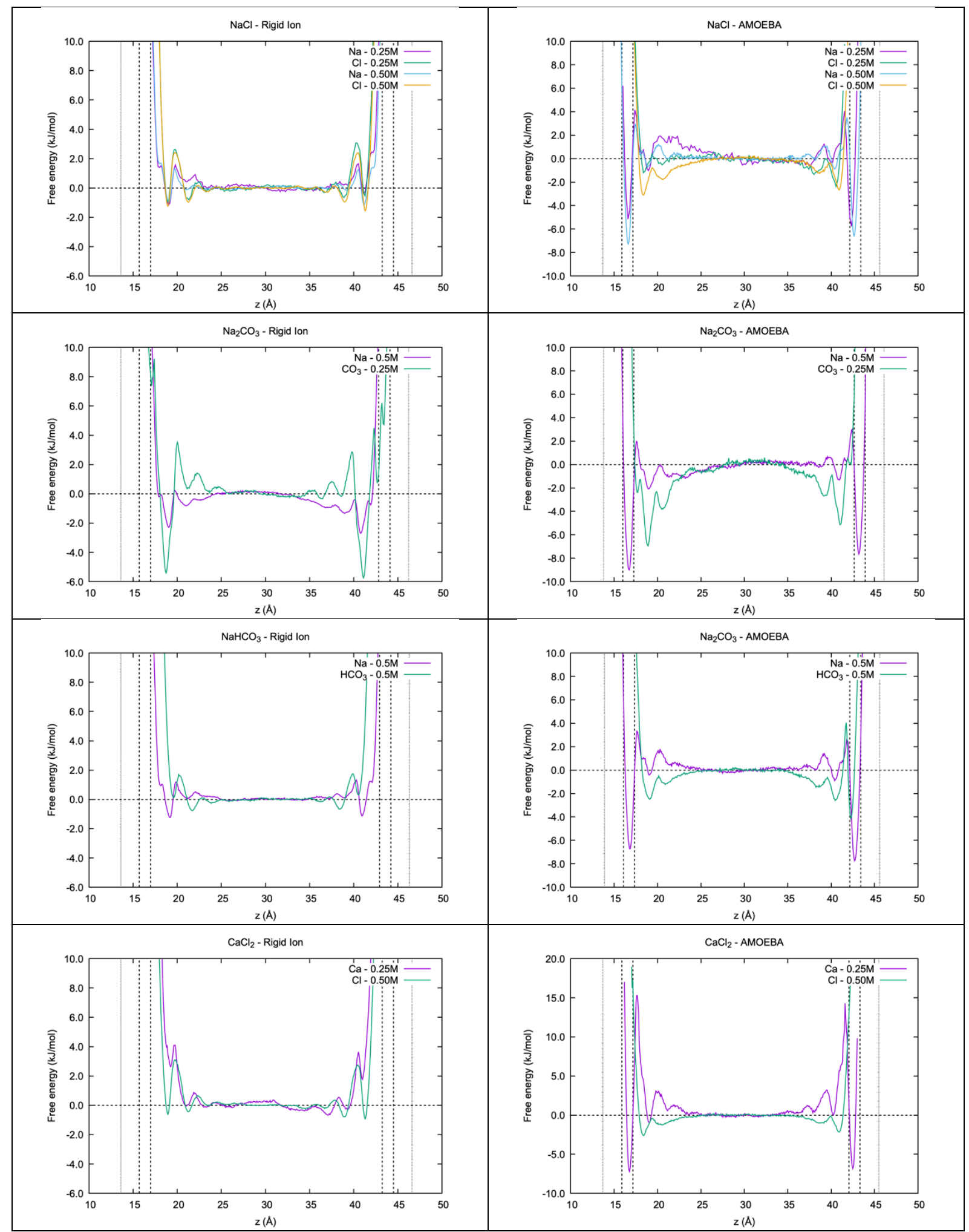

Figure S11: Ion adsorption free energies computed from the density profiles obtained from the MD simulations using the rigid ion (left) and AMOEBA polarizable (right) force fields. The water region is sandwiched between two calcite slabs; the position of the mineral surfaces (dotted lines) was computed as the average position of the surface $\mathrm{Ca}$ ions. The dashed vertical lines indicate the positions of the two ordered water layers above the mineral surfaces. 
Table S5: Comparison of ion binding free energies from SCM (calculated as $\Delta \mathrm{G}=-2.303 \mathrm{RT} \log _{10} \mathrm{IB}$ ) and MD simulations.

\begin{tabular}{|c|c|c|c|c|c|}
\hline & Experiment & \multicolumn{2}{|c|}{ metadynamics } & \multicolumn{2}{c|}{ density } \\
\hline$[\mathrm{kJ} / \mathrm{mol}]$ & $\mathrm{SCM}$ & RigidFF & AMOEBA & RigidFF & AMOEBA \\
\hline$\Delta G_{N a}^{I B}$ & -2.86 & 0 & -10 & -1 & -7 \\
\hline$\Delta G_{C a}^{I B}$ & -3.9 & 0 & -10 & 0 & -7 \\
\hline$\Delta G_{H C O 3}^{I B}$ & -2.12 & 0 & -5 & -1 & -4 \\
\hline$\Delta G_{C O 3}^{I B}$ & -10.95 & -7 & -4 & -5 & -6 \\
\hline$\Delta G_{C l}^{I B}$ & -3.44 & -4 & -2 & -1 & -3 \\
\hline
\end{tabular}

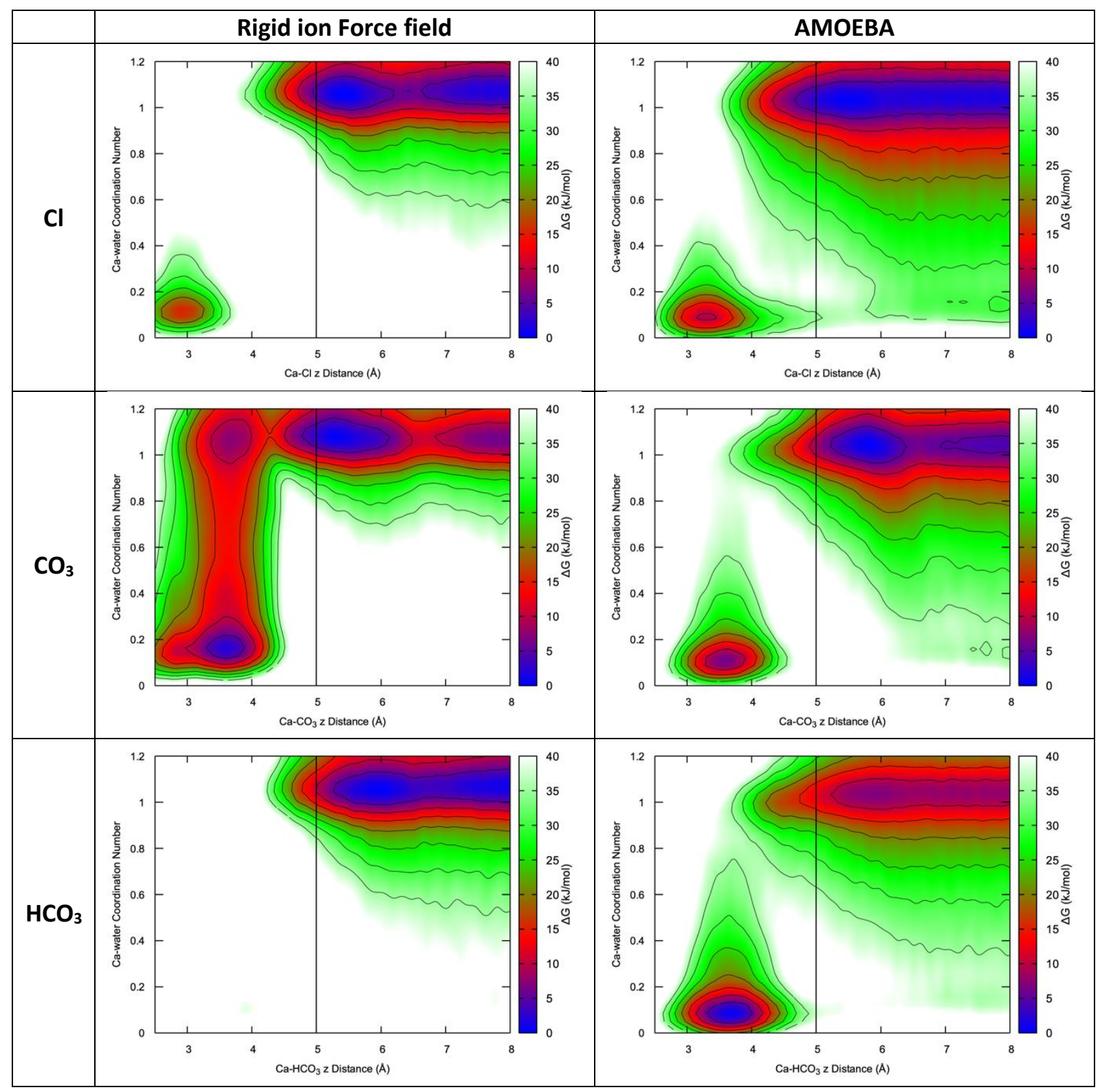

Figure S12: Two-dimensional free energy landscapes for chloride, carbonate and bicarbonate anions close to the hydrated calcite surface as computed from the rigid ion (left) and AMOEBA polarizable 
(right) force fields. The vertical black line indicates the maximum distance from the surface explored by the $a b$ initio molecular dynamics simulations and is added to facilitate comparison.

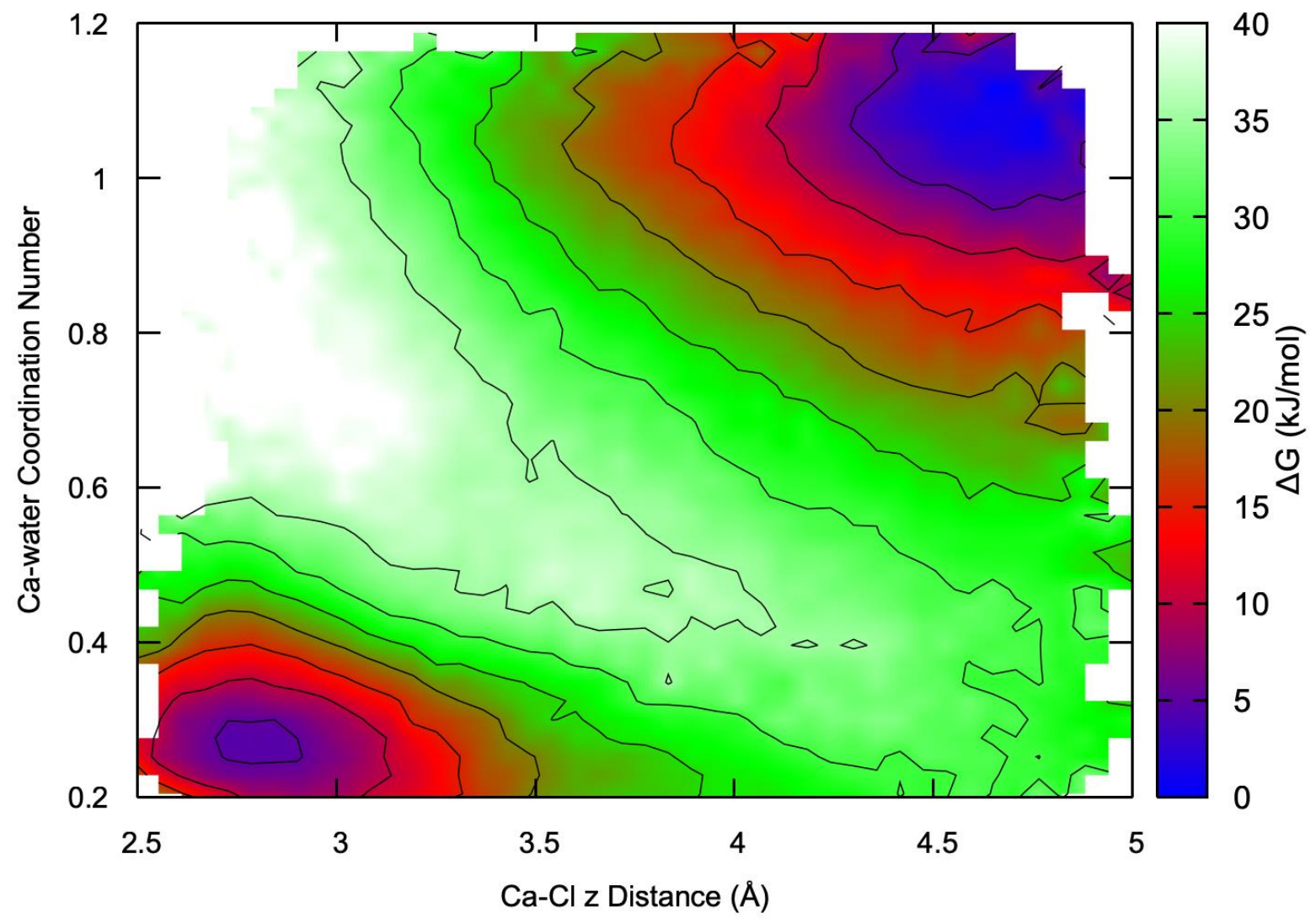

Figure S13: Two-dimensional free energy landscape for the chloride anion close to the hydrated calcite surface as computed from $a b$ initio molecular dynamics at the BLYP-D3/TZV2P level of theory. The free energy surface was determined using umbrella sampling as a function of the $\mathrm{Ca}$ (surface)- $\mathrm{Cl}$ height normal to the surface and the $\mathrm{Ca}$ (surface)-water coordination number, where $\mathrm{Ca}$ (surface) refers to the calcium in the surface layer closest to chloride. 
Table S6: Parameters for the four layer model (FLM) implementation of the SCM, discussed in the main manuscript and presented below in Figure S14.

\begin{tabular}{|c|c|c|}
\hline \multirow[t]{2}{*}{$\begin{array}{c}\text { FLM } \\
\text { Parameters }\end{array}$} & \multicolumn{2}{|c|}{ Best fit SCM } \\
\hline & Value & Std-dev \\
\hline $\log _{10} \mathrm{~K}_{\mathrm{CaOH}}$ & 13.38 & 0.01 \\
\hline $\log _{10} \mathrm{~K}_{\mathrm{CO}} \mathrm{H}$ & 1.3 & 0.1 \\
\hline $\log _{10} I B_{N a}$ & 0.5 & 0.1 \\
\hline $\log _{10} I \mathrm{BCa}$ & 0.68 & 0.02 \\
\hline $\log _{10} I_{\mathrm{BHCO}}$ & 0.37 & 0.09 \\
\hline $\log _{10} \mid B_{C O 3}$ & 1.91 & 0.07 \\
\hline $\log _{10} \mid B_{C l}$ & 0.6 & 0.2 \\
\hline$C_{1}\left(F / m^{2}\right)$ & 0.2 & fixed \\
\hline$C_{2}\left(F / m^{2}\right)$ & 0.6 & m.a* \\
\hline$C_{2}\left(F / m^{2}\right)$ & 4.5 & m.a \\
\hline $\mathrm{CD} \mathrm{Na}$ & $0.0,0.95,0.05, \quad 0.0$ & m.a \\
\hline $\mathrm{CD} \mathrm{Ca}$ & $0.0, \quad 0.0, \quad 2.0, \quad 0.0$ & m.a \\
\hline $\mathrm{CD} \mathrm{HCO}_{3}$ & $0.0,-0.8, \quad-0.2, \quad 0.0$ & m.a \\
\hline $\mathrm{CDCO}_{3}$ & $0.0,-1.75,-0.25, \quad 0.0$ & m.a \\
\hline $\mathrm{CD} \mathrm{Cl}$ & $0.0,-1.0, \quad 0.0, \quad 0.0$ & m.a \\
\hline
\end{tabular}

*) m.a: Parameters denoted m.a. in Table S6 were manually adjusted during SCM optimization
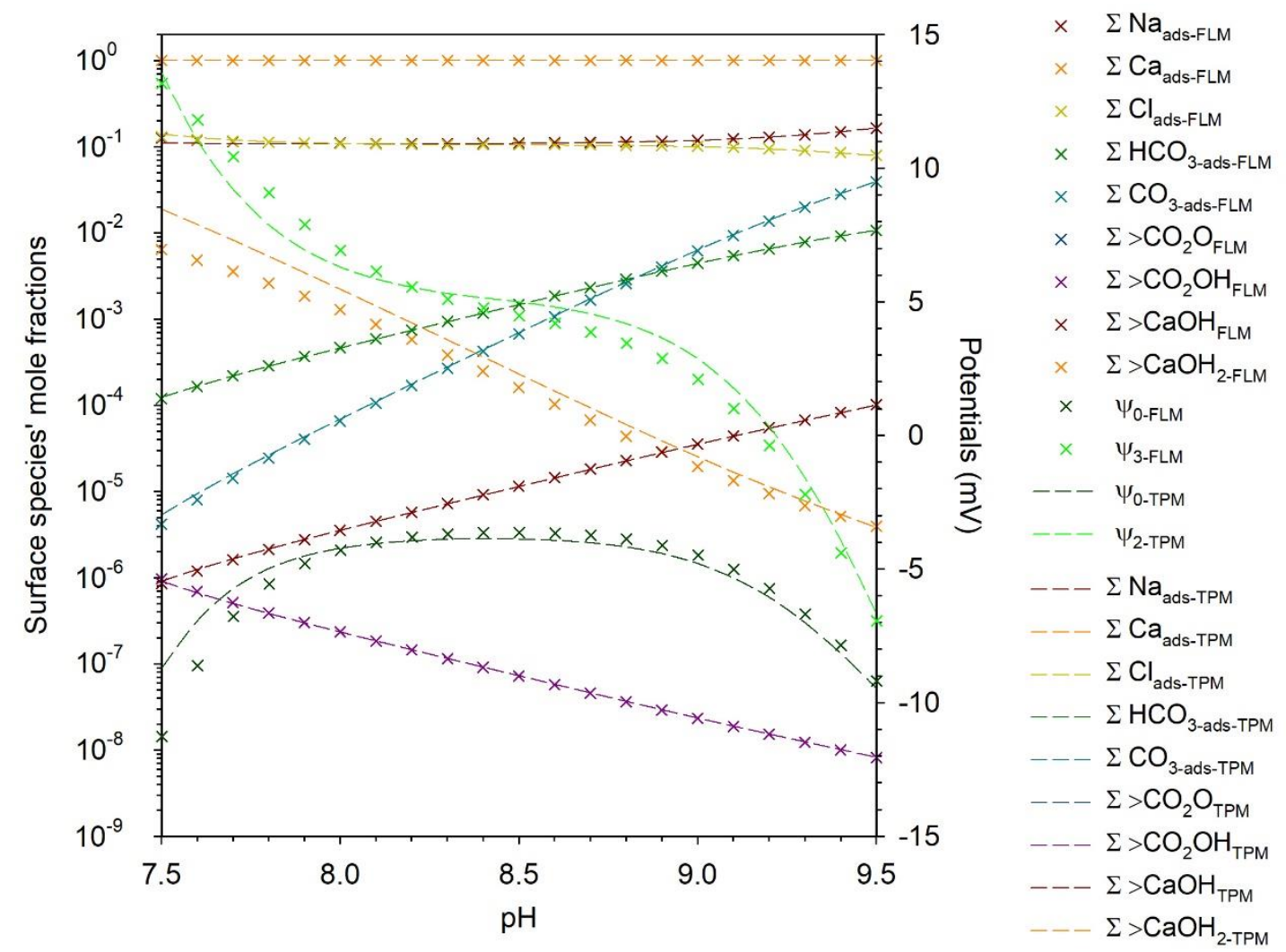

Figure S14: Comparison: FLM (open symbols) - TPM (lines). With the same protonation constants and ion binding parameters the FLM predicts slightly less Ca adsorption, especially at low $\mathrm{pH}$. This has a minor impact on the simulated inner-surface- (0-plane) potential. The zetapotential (2-plane- (TPM) or 3-plane potential (FLM)) curve is less S-shaped. Otherwise the results are very similar. 


\section{PhreeqC Model}

In the following, the PhreeqC code used to calculate results shown in Figure $4 \mathrm{~b}$ is presented. In order to reproduce the data in Figure $4 \mathrm{~b}$, this code must be used together with the PSINA.dat thermodynamic database ${ }^{14}$. The same code is also available in the ESI as PhreeqC input file (calcite-water-interfacemodel.phr):

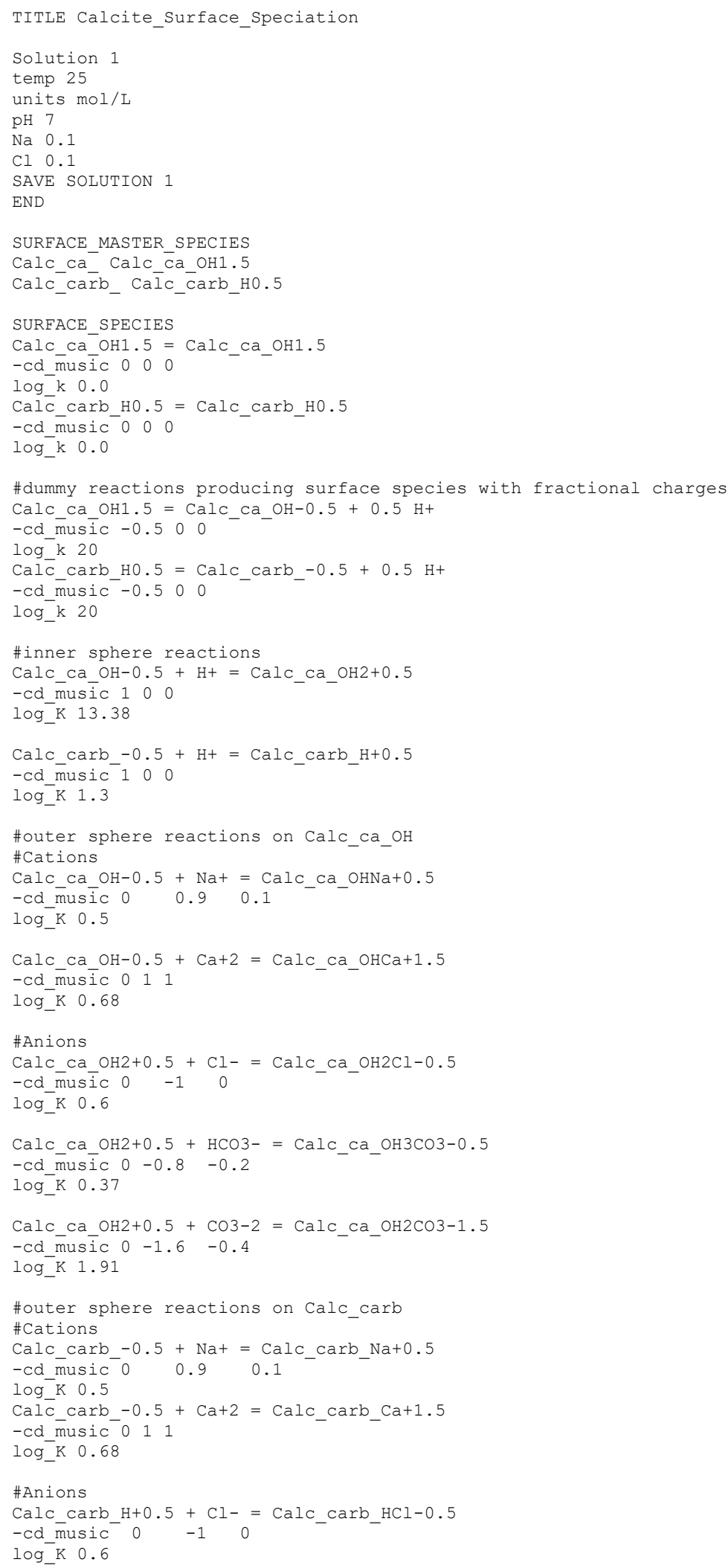




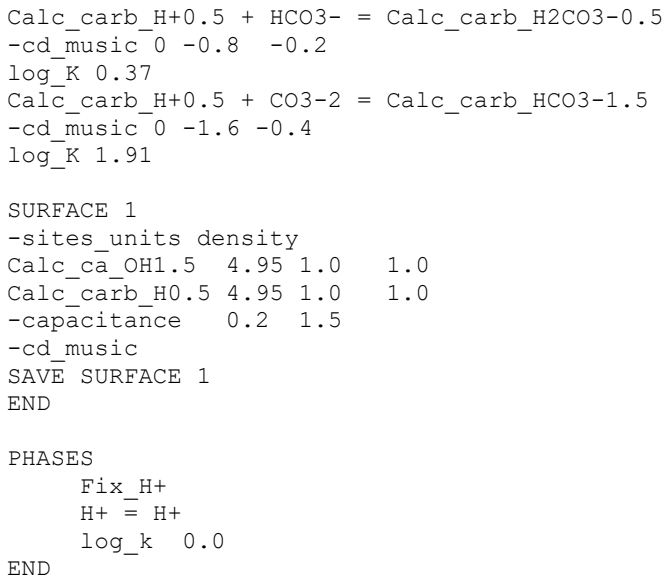

USER_PUNCH

-headings psiO psi2 Na-ads Ca-ads Cl-ads HCO3-ads $\mathrm{CO} 3$-ads sum $>\mathrm{CO} 3$ sum $>\mathrm{CO} 3 \mathrm{H}$ sum $>\mathrm{CaOH}$ sum $>\mathrm{CaOH} 2$ -start

10 punch EDL ("psi", "Calc") $\star 1000$

20 punch EDL ("psi2", "Calc") *1000

30 punch (mol ("Calc_Carb_Na+0.5") + mol ("Calc_ca_OHNa+0.5")) / (8.219e-6*2)

40 punch (mol ("Calc_carb_Ca+1.5") + mol ("Calc_ca_oHCa+1.5")) / (8.219e-6*2)

50 punch (mol ("Calc ${ }^{-} \mathrm{ca}$ O $\left.\left.\overline{\mathrm{H}} 2 \mathrm{Cl}-0.5 "\right)+\operatorname{mol}(" \mathrm{Cal} \overline{\mathrm{C}} \mathrm{c} \overline{\mathrm{r} b} \mathrm{HCl}-0.5 ")\right)$ / (8.219e-6*2)

60 punch (mol ("Calc_ca_OH3CO3-0.5") + mol ("Calc_carb_H2CO3-0.5")) / (8.219e-6*2)

70 punch (mol ("Calc_ca_OH2CO3-1.5") + mol ("Calc_carb_HCO3-1.5")) / (8.219e-6*2)

80 punch (mol ("Calc_carb_-0.5") + mol ("Calc_carb_Ca+1.5") + mol ("Calc_carb_Na+0.5")) / (8.219e-6)

90 punch (mol ("Calc_carb_H+0.5") + mol ("Calc_carb_HCl-0.5") + mol ("Calc_carb H2CO3-0.5") +

mol ("Calc carb HCO3-1.5")) / (8.219e-6)

100 punch $^{-}$(mol ("Calc_ca_oH-0.5") + mol ("Calc_ca_OHNa+0.5") + mol ("Calc_ca_oHCa+1.5")) / (8.219e-6)

110 punch (mol ("Calc_ca_oH2+0.5") + mol ("Calc_cāoH2Cl-0.5") + mol ("Calc_ca_oH3CO3-0.5") + mol ("Calc_ca_OH $2 \mathrm{CO} 3-\overline{1} .5 \bar{"})) /(8.219 \mathrm{e}-6)$

-end

SELECTED OUTPUT

-file CaĪcite_SCM_example_output.dat -reset false

$-\mathrm{pH}$

\#Equilibrium with calcite and air

USE solution 1; USE surface 1; equilibrium_phases; Fix_H+ -7.5 HCl; CO2(g) -3.44; Calcite 0 10; END; USE solution 1; USE surface 1; equilibrium phases; Fix_H+ -7.6 HCl; CO2(g) -3.44; Calcite 0 10; END; USE solution 1; USE surface 1; equilibrium phases; Fix H+ -7.7 HCl; CO2(g) -3.44; Calcite 0 10; END; USE solution 1; USE surface 1; equilibrium_phases; Fix_H+ -7.8 HCl; CO2(g) -3.44; Calcite 0 10; END; USE solution 1; USE surface 1; equilibrium_phases; Fix_H+ -7.9 HCl; CO2(g) -3.44; Calcite 0 10; END; USE solution 1; USE surface 1; equilibrium_phases; Fix_H+ -8.0 HCl; CO2(g) -3.44; Calcite 0 10; END; USE solution 1; USE surface 1; equilibrium phases; Fix H+ -8.1 HCl; CO2(g) -3.44; Calcite 0 10; END; USE solution 1; USE surface 1; equilibrium phases; Fix H+ -8.2 HCl; CO2(g) -3.44; Calcite 0 10; END; USE solution 1; USE surface 1; equilibrium_phases; Fix_H+ -8.3 HCl; CO2(g) -3.44; Calcite 0 10; END; USE solution 1; USE surface 1; equilibrium_phases; Fix_H+ -8.4 NaOH; CO2(g) -3.44; Calcite 0 10; END; USE solution 1; USE surface 1; equilibrium_phases; Fix_H+ -8.5 NaOH; CO2(g) -3.44; Calcite 0 10; END; USE solution 1; USE surface 1; equilibrium phases; Fix H+ -8.6 NaOH; CO2 (g) -3.44; Calcite 0 10; END; USE solution 1; USE surface 1; equilibrium phases; Fix H+ -8.7 NaOH; CO2(g) -3.44; Calcite 0 10; END; USE solution 1; USE surface 1; equilibrium_phases; Fix_H+ -8.8 NaOH; CO2(g) -3.44; Calcite 0 10; END; USE solution 1; USE surface 1; equilibrium_phases; Fix_H+ -8.9 NaOH; CO2(g) -3.44; Calcite 0 10; END; USE solution 1; USE surface 1; equilibrium phases; Fix H+ -9.0 NaOH; CO2(g) -3.44; Calcite 0 10; END; USE solution 1; USE surface 1; equilibrium phases; Fix H+ -9.1 NaOH; CO2 (g) -3.44; Calcite 0 10; END; USE solution 1; USE surface 1; equilibrium phases; Fix H+ -9.2 NaOH; CO2(g) -3.44; Calcite 0 10; END; USE solution 1; USE surface 1; equilibrium_phases; Fix_H+ -9.3 NaOH; CO2(g) -3.44; Calcite 0 10; END; USE solution 1; USE surface 1; equilibrium_phases; Fix_H+ -9.4 NaOH; CO2(g) -3.44; Calcite 0 10; END; USE solution 1; USE surface 1; equilibrium_phases; Fix_H+ -9.5 NaOH; CO2(g) -3.44; Calcite 0 10; END; 
CIF-File type information, to display the best fit interface structure in crystal structure viewer.

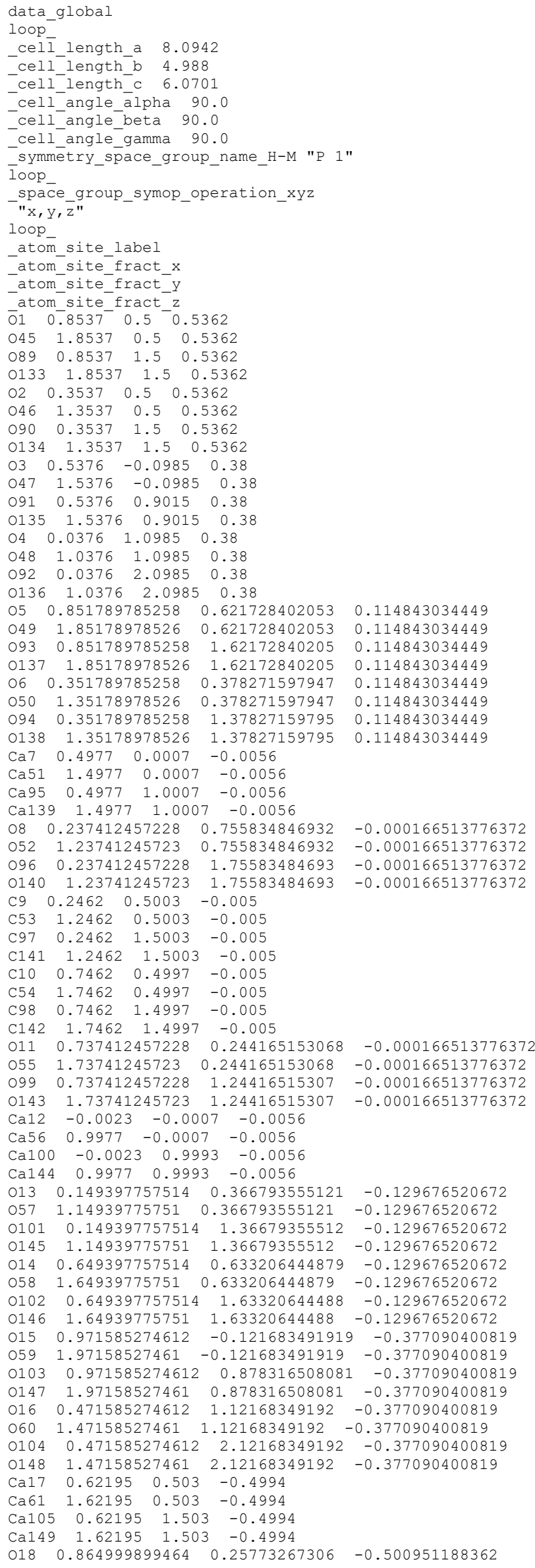




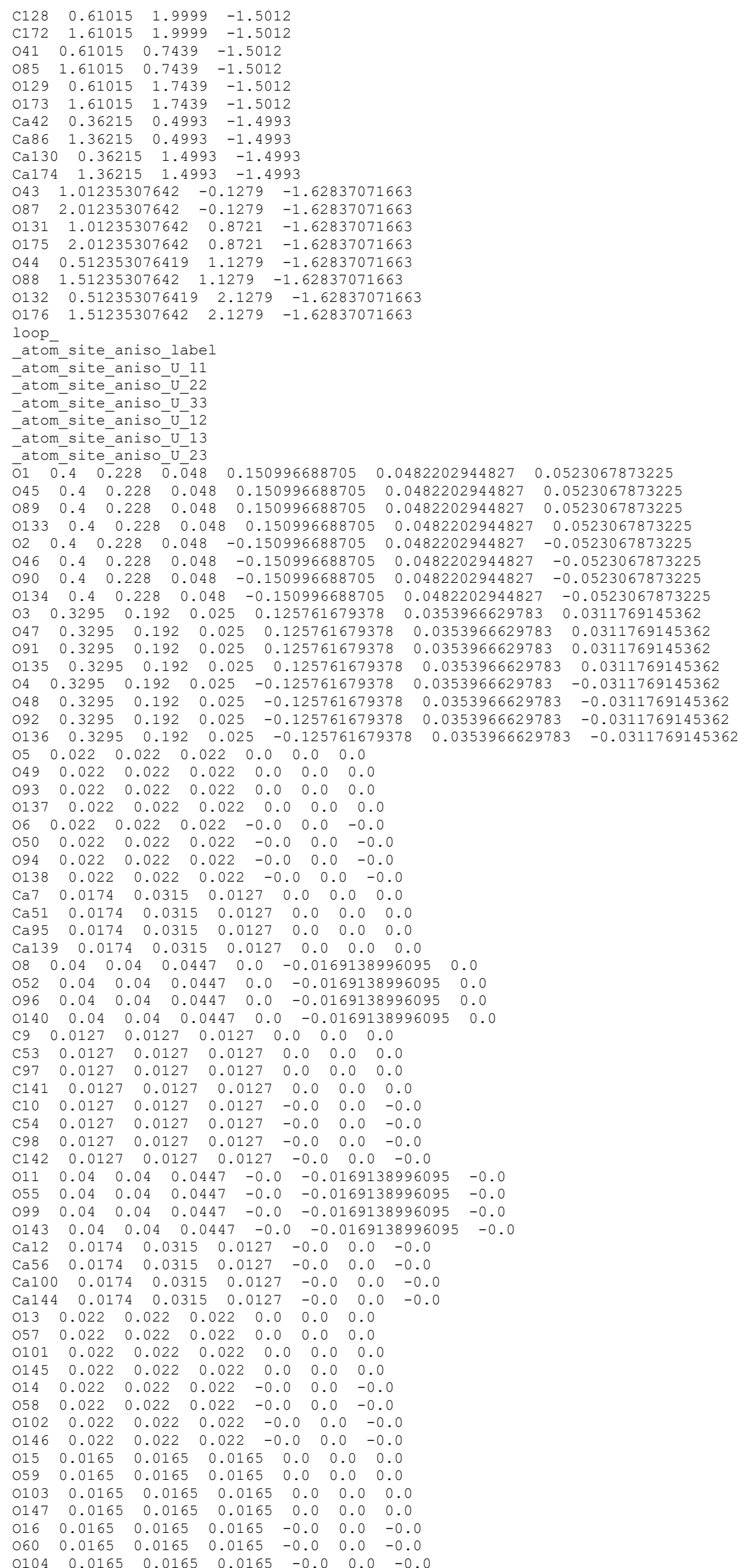




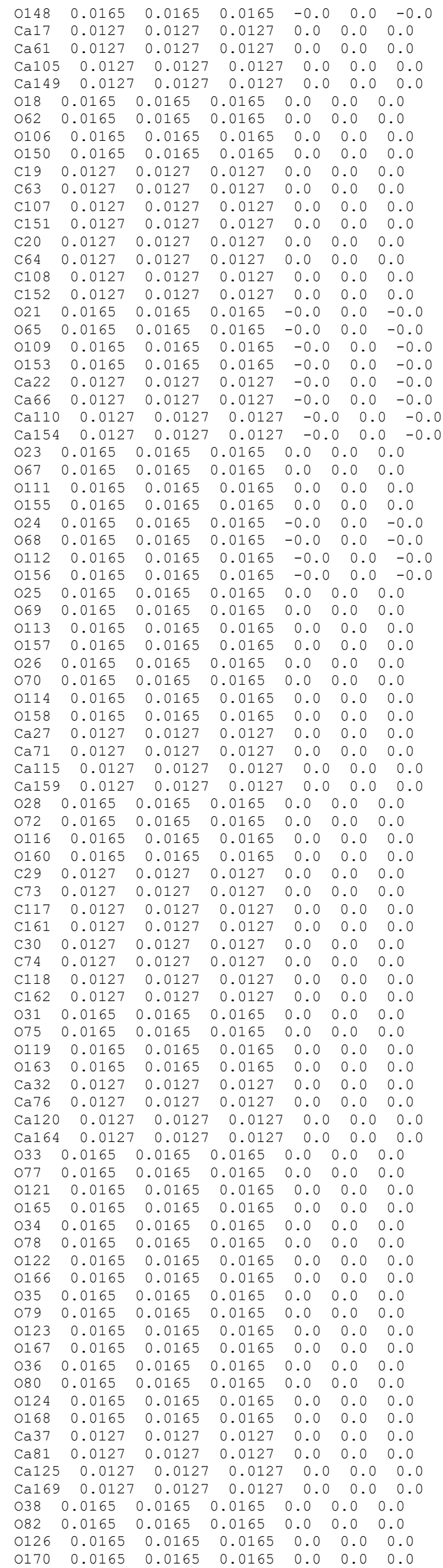


$\begin{array}{lllllll}\text { C39 } & 0.0127 & 0.0127 & 0.0127 & 0.0 & 0.0 & 0.0\end{array}$

$\begin{array}{lllllll}\text { C83 } & 0.0127 & 0.0127 & 0.0127 & 0.0 & 0.0 & 0.0\end{array}$

$\begin{array}{lllllllll}\mathrm{C} 127 & 0.0127 & 0.0127 & 0.0127 & 0.0 & 0.0 & 0.0\end{array}$

$\begin{array}{lllllll}\mathrm{C} 171 & 0.0127 & 0.0127 & 0.0127 & 0.0 & 0.0 & 0.0\end{array}$

$\begin{array}{lllllll}\mathrm{C} 40 & 0.0127 & 0.0127 & 0.0127 & 0.0 & 0.0 & 0.0\end{array}$

$\begin{array}{lllllll}\mathrm{C} 84 & 0.0127 & 0.0127 & 0.0127 & 0.0 & 0.0 & 0.0\end{array}$

$\begin{array}{lllllll}\mathrm{C} 128 & 0.0127 & 0.0127 & 0.0127 & 0.0 & 0.0 & 0.0\end{array}$

$\begin{array}{lllllll}\mathrm{C} 172 & 0.0127 & 0.0127 & 0.0127 & 0.0 & 0.0 & 0.0\end{array}$

$\begin{array}{lllllll}041 & 0.0165 & 0.0165 & 0.0165 & 0.0 & 0.0 & 0.0\end{array}$

$\begin{array}{lllllll}085 & 0.0165 & 0.0165 & 0.0165 & 0.0 & 0.0 & 0.0\end{array}$

$\begin{array}{lllllll}0129 & 0.0165 & 0.0165 & 0.0165 & 0.0 & 0.0 & 0.0\end{array}$

$\begin{array}{lllllll}0173 & 0.0165 & 0.0165 & 0.0165 & 0.0 & 0.0 & 0.0\end{array}$

$\begin{array}{lllllll}\mathrm{Ca} 42 & 0.0127 & 0.0127 & 0.0127 & 0.0 & 0.0 & 0.0\end{array}$

$\begin{array}{lllllll}\text { Ca86 } & 0.0127 & 0.0127 & 0.0127 & 0.0 & 0.0 & 0.0\end{array}$

$\begin{array}{lllllll}\text { Ca130 } & 0.0127 & 0.0127 & 0.0127 & 0.0 & 0.0 & 0.0\end{array}$

$\begin{array}{lllllll}\mathrm{Ca} 174 & 0.0127 & 0.0127 & 0.0127 & 0.0 & 0.0 & 0.0\end{array}$

$\begin{array}{lllllll}043 & 0.0165 & 0.0165 & 0.0165 & 0.0 & 0.0 & 0.0\end{array}$

$\begin{array}{lllllll}087 & 0.0165 & 0.0165 & 0.0165 & 0.0 & 0.0 & 0.0\end{array}$

$\begin{array}{lllllll}0131 & 0.0165 & 0.0165 & 0.0165 & 0.0 & 0.0 & 0.0\end{array}$

$\begin{array}{lllllll}0175 & 0.0165 & 0.0165 & 0.0165 & 0.0 & 0.0 & 0.0\end{array}$

$\begin{array}{lllllll}044 & 0.0165 & 0.0165 & 0.0165 & 0.0 & 0.0 & 0.0\end{array}$

$\begin{array}{lllllll}088 & 0.0165 & 0.0165 & 0.0165 & 0.0 & 0.0 & 0.0\end{array}$

$\begin{array}{lllllll}0132 & 0.0165 & 0.0165 & 0.0165 & 0.0 & 0.0 & 0.0\end{array}$

$\begin{array}{lllllll}0176 & 0.0165 & 0.0165 & 0.0165 & 0.0 & 0.0 & 0.0\end{array}$ 


\section{References}

1. Plimpton, S., Fast Parallel Algorithms for Short-Range Molecular Dynamics. Journal of Computational Physics 1995, 117, (1), 1-19.

2. $\quad$ Eastman, P.; Swails, J.; Chodera, J. D.; McGibbon, R. T.; Zhao, Y.; Beauchamp, K. A.; Wang, L.P.; Simmonett, A. C.; Harrigan, M. P.; Stern, C. D., OpenMM 7: Rapid development of high performance algorithms for molecular dynamics. PLoS computational biology 2017, 13, (7), e1005659.

3. Raiteri, P.; Schuitemaker, A.; Gale, J. D., Ion Pairing and Multiple lon Binding in Calcium Carbonate Solutions Based on a Polarizable AMOEBA Force Field and Ab Initio Molecular Dynamics. The Journal of Physical Chemistry B 2020, 124, (17), 3568-3582.

4. Becke, A. D., Density-functional thermochemistry. I. The effect of the exchange-only gradient correction. The Journal of chemical physics 1992, 96, (3), 2155-2160.

5. Lee, C.; Yang, W.; Parr, R. G., Development of the Colle-Salvetti correlation-energy formula into a functional of the electron density. Physical review B 1988, 37, (2), 785.

6. Grimme, S.; Antony, J.; Ehrlich, S.; Krieg, H., A consistent and accurate ab initio parametrization of density functional dispersion correction (DFT-D) for the 94 elements H-Pu. The Journal of chemical physics 2010, 132, (15), 154104.

7. VandeVondele, J.; Krack, M.; Mohamed, F.; Parrinello, M.; Chassaing, T.; Hutter, J., Quickstep: Fast and accurate density functional calculations using a mixed Gaussian and plane waves approach. Comput Phys Commun 2005, 167, (2), 103-128.

8. Hutter, J.; Iannuzzi, M.; Schiffmann, F.; VandeVondele, J., cp2k: atomistic simulations of condensed matter systems. Wiley Interdisciplinary Reviews: Computational Molecular Science 2014, 4, (1), 15-25.

9. Goedecker, S.; Teter, M.; Hutter, J., Separable dual-space Gaussian pseudopotentials. Physical Review B 1996, 54, (3), 1703.

10. Heberling, F.; Trainor, T. P.; Lützenkirchen, J.; Eng, P.; Denecke, M. A.; Bosbach, D., Structure and reactivity of the calcite-water interface. Journal of Colloid and Interface Science 2011, 354, (2), 843-857.

11. Robinson, I. K., Crystal truncation rods and surface roughness. Physical Review B 1986, 33, (6), 3830-3836.

12. Fenter, P.; Geissbuhler, P.; DiMasi, E.; Srajer, G.; Sorensen, L. B.; Sturchio, N. C., Surface speciation of calcite observed in situ by high-resolution X-ray reflectivity. Geochimica et Cosmochimica Acta 2000, 64, (7), 1221-1228.

13. Parkhurst, D. L.; Appelo, C., Description of input and examples for PHREEQC version 3-a computer program for speciation, batch-reaction, one-dimensional transport, and inverse geochemical calculations. US geological survey techniques and methods, book 2013, 6, 497.

14. Thoenen, T.; Hummel, W.; Berner, U.; Curti, E. The PSI/Nagra Chemical Thermodynamic Database 12/07; Paul Scherrer Institut: 2014.

15. Fenter, P.; Sturchio, N. C., Mineral-water interfacial structures revealed by synchrotron X-ray scattering. Progress in Surface Science 2004, 77, (5-8), 171-258.

16. Hiemstra, T.; Van Riemsdijk, W.; Bolt, G., Multisite proton adsorption modeling at the solid/solution interface of (hydr) oxides: A new approach: I. Model description and evaluation of intrinsic reaction constants. Journal of Colloid and Interface Science 1989, 133, (1), 91-104.

17. Friesen, S.; Hefter, G.; Buchner, R., Cation Hydration and Ion Pairing in Aqueous Solutions of $\mathrm{MgCl} 2$ and $\mathrm{CaCl} 2$. The Journal of Physical Chemistry B 2019, 123, (4), 891-900.

18. Lee, S. S.; Heberling, F.; Sturchio, N. C.; Eng, P. J.; Fenter, P., Surface Charge of the Calcite (104) Terrace Measured by $\mathrm{Rb}+$ Adsorption in Aqueous Solutions Using Resonant Anomalous X-ray Reflectivity. The Journal of Physical Chemistry C 2016, 120, (28), 15216-15223. 